\title{
Characterization of Dry Conditions across the U.S.-Affiliated Pacific Islands during Near-Neutral ENSO Phases
}

\author{
ALEJANDRO LUDERT \\ Department of Atmospheric Science, and Pacific ENSO Applications Climate Center, University of Hawai'i at \\ Mānoa, Honolulu, Hawaii \\ BIN WANG \\ Department of Atmospheric Science, University of Hawai'i at Mānoa, Honolulu, Hawaii, and Earth System \\ Modeling Center, Nanjing University of Information Science and Technology, Nanjing, China \\ MARK A. MERRIFIELD \\ Department of Oceanography, University of Hawai'i at Mānoa, Honolulu, Hawaii
}

(Manuscript received 18 August 2017, in final form 26 April 2018)

\begin{abstract}
The U.S.-Affiliated Pacific Islands (USAPIs), located in the tropical western Pacific, are very susceptible to severe drought. Dry season (December-May) rainfall anomalies have different relationships to ENSO for USAPIs north and south of $7^{\circ} \mathrm{N}$. South of $7^{\circ} \mathrm{N}$, rainfall exhibits a canonical negative correlation with the Oceanic Niño Index (ONI) (i.e., dry conditions during warm periods). To the north, the dry season falls into either "canonical" or "noncanonical" (positively correlated with ONI) regimes. Noncanonical years pose an important forecasting challenge as severe droughts have occurred during cool ONI conditions (referred to here as "cool dry" cases). Composite analysis of the two regimes shows that for noncanonical cool dry years, anticyclonic circulation anomalies over the tropical western North Pacific (TWNP), with a band of anomalous dry conditions extending from the central Pacific toward Micronesia, result in unexpected droughts. In contrast, canonical "cool wet" events show cyclonic TWNP circulation and increased rainfall over the northern USAPIs. Maximum SST anomalies are located near the date line during noncanonical years, and farther east during canonical years. While both regimes show negative rainfall and TWNP anticyclonic circulation anomalies before the onset of the December-May dry season, during the dry season these anomalies persist during noncanonical events but rapidly reverse sign during canonical events. SST anomalies in the noncanonical regime extend eastward from the central Pacific rather than intensify in place over the eastern Pacific in the canonical regime. Differences in the evolution of circulation, precipitation, and SST anomalies suggest distinct physical mechanisms governing the two ENSO regimes, with possible ramifications for seasonal forecasts.
\end{abstract}

\section{Introduction}

The United States-Affiliated Pacific Islands (USAPIs; Fig. 1) are composed of U.S. territories (Guam, American Samoa, and the Commonwealth of the Northern Mariana Islands) and independent nations that are in free association with the United States [the Republic of Palau, the Republic of the Marshall Islands (RMI), and the Federated States of Micronesia]. The low-lying atolls and higher-elevation islands of the region have small landmass, remote location, and limited financial

Corresponding author: Alejandro Ludert, aludert@hawaii.edu and natural resources, making the USAPIs particularly vulnerable to the impacts of climate variability (Shea et al. 2001). Positioned in the tropical western Pacific, the climate of the USAPIs is strongly modulated by El Niño-Southern Oscillation (ENSO; Bjerknes 1966, 1969; McPhaden et al. 2006). The effects of ENSO on the USAPIs include changes in seasonal rainfall ( $\mathrm{Yu}$ et al. 1997), tropical cyclone activity (Lander 1994; Wang and Chan 2002), and sea surface temperature (SST; Wang et al. 1999; Chowdhury et al. 2007) variability.

During energetic El Niño and La Niña events, rainfall variations north of the equator in the USAPIs relate directly to the shift in the position of the intertropical 


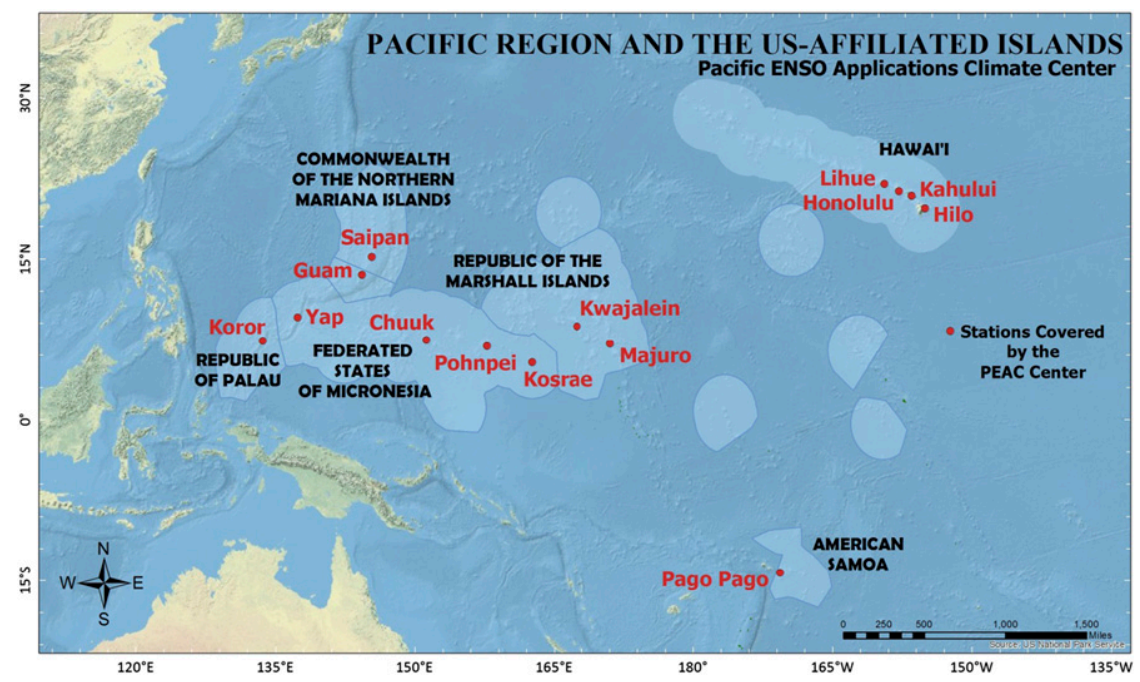

FIG. 1. Map showing the U.S. territories and independent nations that compose the U.S.-Affiliated Pacific Islands. Marked in red are the stations for which the PEAC Center produces seasonal rainfall forecasts.

convergence zone (ITCZ) (Collins et al. 2011). In general, in a year when El Niño conditions develop, ITCZ convection shifts eastward from the Pacific warm pool toward the date line, producing wetter than normal conditions in the USAPIs during boreal fall. As the El Niño matures, convection is enhanced east of the date line and suppressed to the west, causing anomalously low rainfalls during the climatological dry season (DecemberMay) across the USAPI region, as observed during early 1983 and 1998 (Ropelewski and Halpert 1987; Murphy et al. 2014). The intensity of El Niño-induced dry conditions across the USAPIs is proportional to the magnitude of the El Niño event, with 1982/83 and 1997/98 producing intense and widespread droughts throughout the region (Schroeder et al. 2012).

Current understanding of ENSO is that El Niño events can display different "flavors," with distinct characteristics in SST anomaly patterns and local and global impacts (Kao and Yu 2009; Kug et al. 2009). Eastern Pacific or cold tongue El Niño events are characterized by having their strongest SST anomalies over the eastern Pacific, while central Pacific, warm pool, or "Modoki" El Niño events show SST anomalies confined to the central Pacific near the date line. Differences in SST anomaly patterns lead to differences in atmospheric circulation anomalies and hence result in differences in the regional and global impacts of these two types of El Niño events (Cai and Cowan 2009; Ashok et al. 2007; Weng et al. 2007; Taschetto and England 2009; Weng et al. 2009). While the existence of different types of ENSO events is well acknowledged, there is still significant debate as to whether these types represent distinct modes of variability or whether ENSO should be understood as a diverse continuum (Capotondi et al. 2015). In terms of the relative importance of dynamical processes, thermocline anomalies and recharge-discharge dynamics are more prominent during cold tongue El Niño events and zonal advective feedback and air-sea heat fluxes in this region are more prominent in warm pool events (Kao and Yu 2009; Kug et al. 2009, 2010; Yu et al. 2010). In this work, we use the warm pool, mixed, and cold tongue terminology consistent with Kug et al. (2009).

The different types of El Niño events exhibit different rainfall patterns. Based on station rainfall data, Murphy et al. (2014) find that cold tongue El Niño events produce consistent dry conditions across all of the USAPI stations, mixed El Niño events are associated with dry conditions in the western USAPIs and the southern Marshall Islands only, and warm pool El Niño events produce dry conditions only in the westernmost USAPI station of Koror.

Unlike El Niño events, SST patterns associated with La Niña events do not exhibit a clear separation into types (Kug et al. 2009). This is because, in general, La Niña events tend to have peak SST anomalies farther west than El Niño events, resulting in fewer interevent differences in SST patterns. As a result, much of the research into ENSO flavors has been concentrated on warm events exclusively. La Niña events tend to produce wet conditions north of about $5^{\circ} \mathrm{N}$ (Murphy et al. 2014).

Severe drought impacts can also occur in the USAPIs during near-neutral ENSO conditions. During the early part of 2013, persistent anomalous dry conditions worsened the climatological dry season in atolls and islands in the northern part of the RMI. From January to 
May 2013, Kwajalein, used here as a proxy for the northern RMI, received less than $380 \mathrm{~mm}$ (15 in.) of rainfall total, which is far less than the roughly $100 \mathrm{~mm} \mathrm{month}^{-1}$ most USAPIs need to meet basic water needs [based on an internal Pacific ENSO Applications Climate (PEAC) Center working estimate]. The extended 2013 drought event prompted emergency and disaster declarations from both local and international governments. By the end of the event, a total of about $\$ 4.5$ million dollars in relief funds had been invested by the U.S. Government for an event that affected an estimated 6400 people. PEAC rainfall forecasts showed low skill during the duration of this drought period, which is common for ENSO-neutral periods in general.

In this paper, we examine rainfall anomalies across the northern USAPIs during near-neutral ENSO conditions to determine if regional patterns are present that might lead to improved forecasting skill. American Samoa will be excluded from this study due to its location in the South Pacific. We evaluate the 2013 drought event in the USAPI region and examine the mechanisms contributing to the dry conditions. Section 2 describes the data and methodology used in selecting and examining the features associated with dry conditions in the USAPIs during nearneutral ENSO conditions. In section 3 we identify stations with coherent rainfall variability. Section 4 showcases our methodology for choosing composite members. Sections 5 and 6 show the differences in dry season rainfall for composite members and their evolution leading up to the dry season. In section 7 we discuss our results and describe the proposed mechanisms that produce dry conditions in the USAPIs during near-neutral ENSO conditions.

\section{Methodology and data}

\section{a. Station rainfall data and observed impacts information}

Precipitation data are recorded by the NOAA National Centers for Environmental Information (NCEI) through their Automated Surface Observing System as well as reported directly to the PEAC. PEAC rainfall data are consistent with what is archived for these stations by the NCEI for the major USAPI stations, with NCEI archiving data for many more minor USAPI stations. Continuous monthly total rainfall data are available for Koror, Yap, Chuuk, Pohnpei, Guam, Kwajalein, and Majuro from 1966 to present. For USAPI stations for which PEAC does not archive rainfall data, monthly rainfall totals from the Cooperative Observer Network (COOP) stations and historical rainfall data archived by the Western Regional Climate Center (WRCC) were used. COOP and WRCC station data are available for many USAPI stations including many outer islands and atolls, and the dataset covers areas of interest such as the northern RMI atolls of Enewetak, Wotje, and Utirik for which most of the severe impacts of the 2013 drought were observed. Unfortunately, data for many of these COOP and WRCC stations in the USAPIs suffer from large data gaps, including no data at many stations during 2013. A total of 35 COOP stations across the USAPIs were used along with the seven PEAC stations. COOP data were downloaded from the WRCC (http:// www.wrcc.dri.edu/).

PEAC also collects detailed accounts of climate impacts from contributors in the USAPIs. These recorded impacts are published in the PEAC Quarterly Pacific ENSO Update newsletter, which extends back to 2005 in digital form and 1996 in paper copies (available upon request at www.weather.gov/peac/update).

\section{b. Other data}

The Oceanic Niño Index (ONI) values are made public by the NOAA Climate Prediction Center (CPC) based on the Extended Reconstructed Sea Surface Temperature (ERSST) version v5 (Huang et al. 2017). The ONI is formed from 3-month running means of ERSST.v5 SST anomalies in the Niño-3.4 region $\left(5^{\circ} \mathrm{N}-\right.$ $5^{\circ} \mathrm{S}, 120^{\circ}-170^{\circ} \mathrm{W}$ ). NCEP-NCAR Reanalysis 1 (Kalnay et al. 1996) was used for pressure level data of geopotential heights and winds. The Global Precipitation Climatology Project (GPCP V2.2; Adler et al. 2003) combined monthly precipitation dataset was used for large-scale analysis of rainfall. Gridded ERSST.v4 data were used for SST fields (Huang et al. 2015, 2016). NCEP Global Ocean Data Assimilation System (GODAS) multilevel ocean analysis data were used for calculation of $20^{\circ} \mathrm{C}$ isotherm depth. ERSSTv4, NCEP-NCAR reanalysis, and GODAS, as well as GPCP data, were provided by the NOAA/OAR/ESRL PSD, Boulder, Colorado, at http://www.esrl.noaa.gov/psd/.

\section{c. Methodology}

Given the sparsity of rainfall data in the USAPI region, we group stations with similar annual and interannual variability to obtain long proxy records for the analysis. Using the monthly data available for all COOP and PEAC stations in the USAPIs, a climatological annual cycle of monthly rainfall was calculated for each station. The similarity of the annual cycles for different stations was calculated using the Monsoon Index (Wang and Ding 2008) and a $k$-means clustering algorithm (Lloyd 1982). The Monsoon Index is the annual cycle range calculated as the difference of climatological wet (June-November) and dry (December-May) season rainfalls, divided by the climatological total yearly rainfall and multiplied by 100 . The $k$-means clustering 
was applied to the annual cycle of monthly rainfall of all the stations with each station considered as a data point in 12-dimensional space on which the clustering was performed. The $k$-means algorithm separates data points into clusters by minimizing the within-cluster sum-ofsquare variance, also known as inertia. The $k$-means algorithm was implemented using the Python Scikit-Learn package (Scikit-Learn Developers 2017a) using centroid initialization as $k$-means ++ (Arthur and Vassilvitskii 2007). Selection of the optimal number of a priori clusters was made using the Davies-Bouldin index (Davies and Bouldin 1979). The sample silhouette score is used to estimate how well samples are clustered within a cluster (Scikit-Learn Developers 2017b).

The Standardized Precipitation Index (SPI) for the common dry season was calculated for each station and averaged across all coherent stations to form a single regional drought index (McKee et al. 1993). The regional drought index and the ONI are used to classify canonical and noncanonical conditions. Years with dry conditions and positive ONI values ("warm dry") or wet conditions and negative ONI values ("cool wet") are treated as canonical years. Similarly, years with dry conditions and negative ONI values ("cool dry") or wet conditions and positive ONI values ("warm wet") are noncanonical years.

Composites of SST, precipitation, 850-hPa wind, and geopotential height were generated to analyze the differences in climate conditions that lead to dry and wet conditions in the region under similar ONI regimes. Time-longitude diagrams of monthly data are used to understand the progression of atmospheric and ocean conditions leading up to each type of event. Calculations of atmospheric quantities such as vorticity were performed using the Python package atmqty (available at http://www.johnny-lin.com/py_pkgs/atmqty/doc/) after verifying that tools in this package yielded expected results.

\section{Coherent rainfall station selection}

The USAPI stations analyzed are separated into two distinct rainfall categories, northern and southern stations, based on their annual cycle (Fig. 2). We choose two clusters in the $k$-means algorithm using the number of clusters that minimizes the Davies-Bouldin index. Northern stations exhibit a dry season from December to June, defined as months for which monthly rainfall is less than the annual mean, and a wet season from July to November. The seasonal variability is monsoon-like; however, the corresponding Monsoon Index for northern stations is just above $30 \%$, which is below the required value of $50 \%$ to be considered part of the global monsoon domain (Wang and Ding 2008). Stations most severely affected by the 2013 drought event (Enewetak, Utirik, and Wotje) are all classified into the northern station cluster with anomalous dry conditions coinciding with the climatological dry season. Stations in the southern cluster show a weak biannual oscillation about the annual mean, which is over $100 \mathrm{~mm}$ higher than the northern station mean. The driest times of year are during fall and spring, associated with the northward and southward pass of the ITCZ during its seasonal migration.

Rainfall records for Guam, Kwajalein, and Yap are available since 1966 and are all classified as having a northern type of annual rainfall cycle, similar to those stations most affected by the 2013 drought. The correlations of December to May rainfall anomalies at these stations exceed the $99 \%$ test level for the period 1966 to present. The silhouette score, which measures the distance between a cluster point and the centroid of the nearest cluster, is 0.23 for Yap. This low score indicates that Yap has an annual cycle that, while classified as northern, has some similarity to the mean annual cycle of southern stations. The other northern stations all have higher silhouette scores than Yap.

Because of their common annual cycle and significantly correlated interannual variability, Kwajalein and Guam are chosen as representative stations for rainfall variability in the northern USAPI region, while Majuro and Yap are not used. Koror, Chuuk, Pohnpei, and Kosrae are used for the southern stations. We will define the dry season as the December-May period, which represents the six climatologically driest months in the northern USAPIs. The SPI for total rainfall for December-May was calculated individually for each station and averaged with the SPI values for the other proxy stations in that cluster.

\section{Distinguished canonical and noncanonical ENSO regimes}

The relationship between dry season rainfall, as measured by the SPI, and ONI differs between the northern and southern USAPI stations (Fig. 3). For the strongest El Niño events (i.e., cold tongue events, ONI $\geq 2^{\circ} \mathrm{C}$ ) such as 1983,1998 , and 2016 , severe drought conditions occur during the dry season (December of the previous year to May of the referred year) for both southern and northern USAPI stations. For ONI values less than $2^{\circ} \mathrm{C}$, the southern USAPI stations exhibit a significant negative correlation $(-0.72$, significant at the 99.9\% level) between SPI and ONI, with moderate El Niños producing drier than normal conditions and $\mathrm{La}$ Niñas producing wetter than normal conditions. On the 

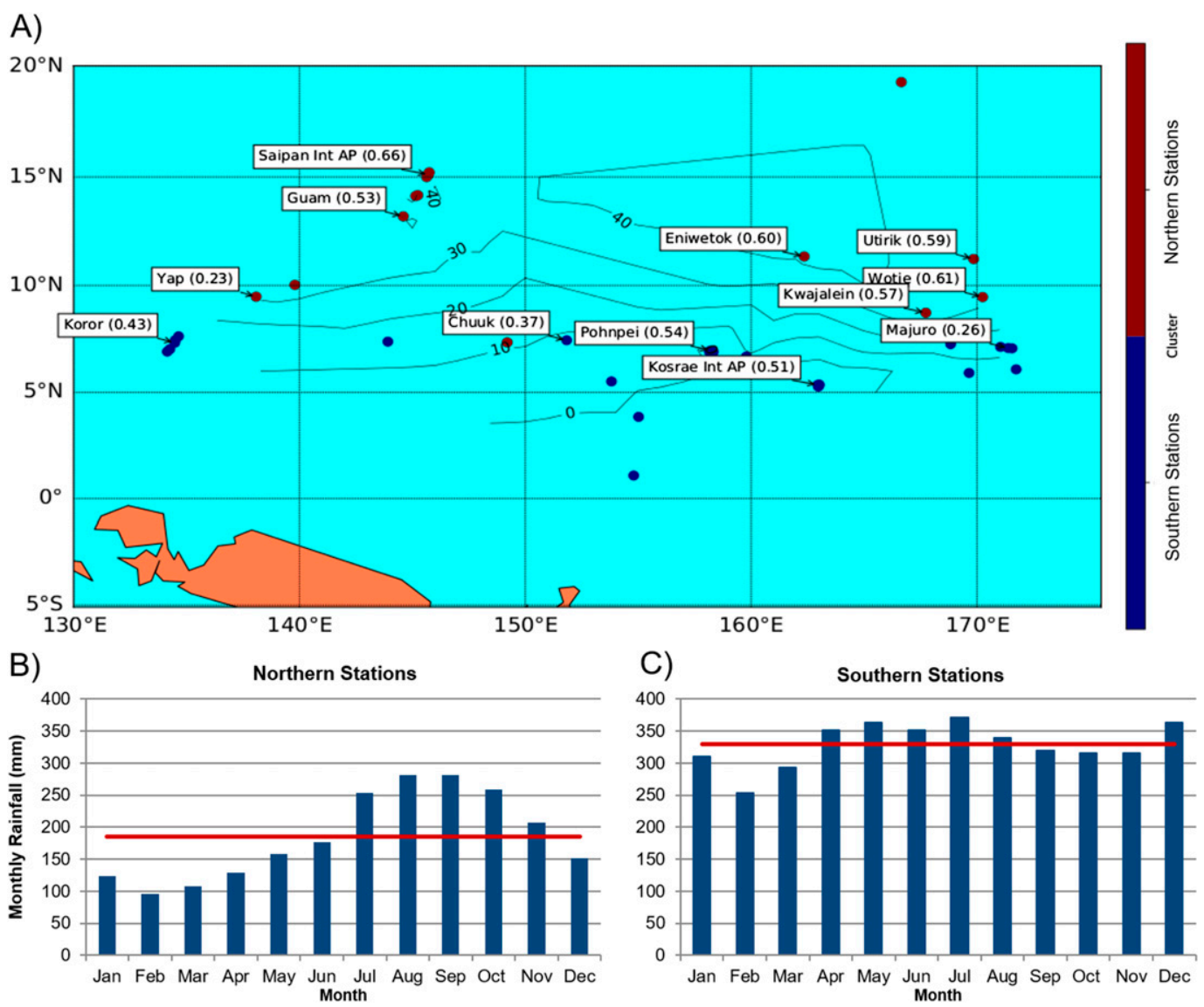

FIG. 2. (a) Map showing the USAPI stations and their assigned $k$-means cluster (color), monsoon index (contours), and silhouette score for the most relevant stations (number next to station name). Also shown are the average annual cycles of stations in the (b) northern and (c) southern clusters.

other hand, rainfall at the northern USAPI stations does not strongly correlate with the ONI. If all years are taken into account, the SPIs in the northern USAPIs and the ONI have a correlation of -0.43 (significant at the $98 \%$ level), but when the strong cold tongue El Niño events of 1983, 1998, and 2016 are excluded, this correlation falls to -0.14 . This low correlation between rainfall and ONI in the northern USAPIs suggests that other factors contribute to rainfall variability in this region beyond the amplitude and phase of ENSO.

The years selected for our composite analysis in section 4 are shown in Fig. 3 with color markers. We focus our analysis on the ONI region between $-1^{\circ}$ and $2^{\circ} \mathrm{C}$ where rainfall variability in the northern USAPI region is highest and exclude years with SPI or ONI values close to zero. In this work, we consider warm dry (red circles) and cool wet (blue circles) years in the northern USAPIs as "canonical" years because they fit our current understanding of the effect of large ENSO events on the rainfall of the tropical western Pacific and the USAPIs specifically. Conversely, cool dry (red diamonds) and warm wet (blue diamonds) years, for which dry season rainfall and December-February (DJF) ONI appear to be positively correlated will be referred to as "noncanonical" years.

Table 1 compares our classification methodology with CPC operational methodology as well as that of Kug et al. (2009) and Murphy et al. (2014). The methodology used in this work yields a different year selection than previous works in which selection was based solely on SST conditions. For events classified as warm pool El Niño events by Kug et al. (2009) and Murphy et al. (2014), both wet and dry impacts over the northern USAPIs are observed. Current commonly used discrimination criteria are not able to separate these distinct events, and composite analyses of these events taken together will not highlight the features that produce these diverse anomalies. Nonetheless, the differences in rainfall between dry and wet events with similar ONI values are significant. Events in the warm wet and warm dry categories have a difference in mean SPI value significant at the $99.9 \%$ test level with a $p$ value of $1 \times 10^{-4}$ (the null hypothesis being 
A) Northern USAPIs

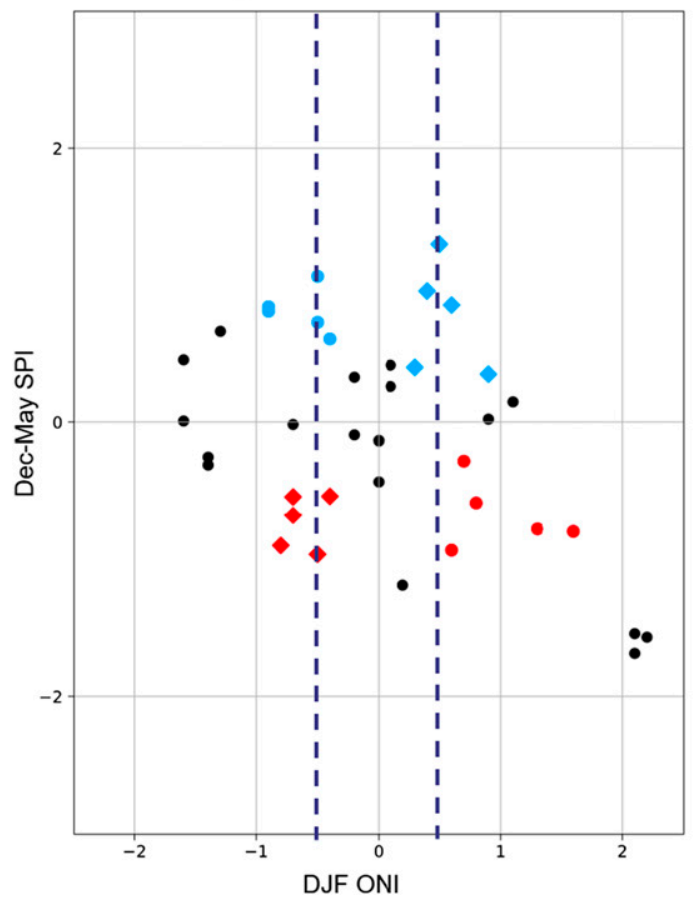

B) Southern USAPIs

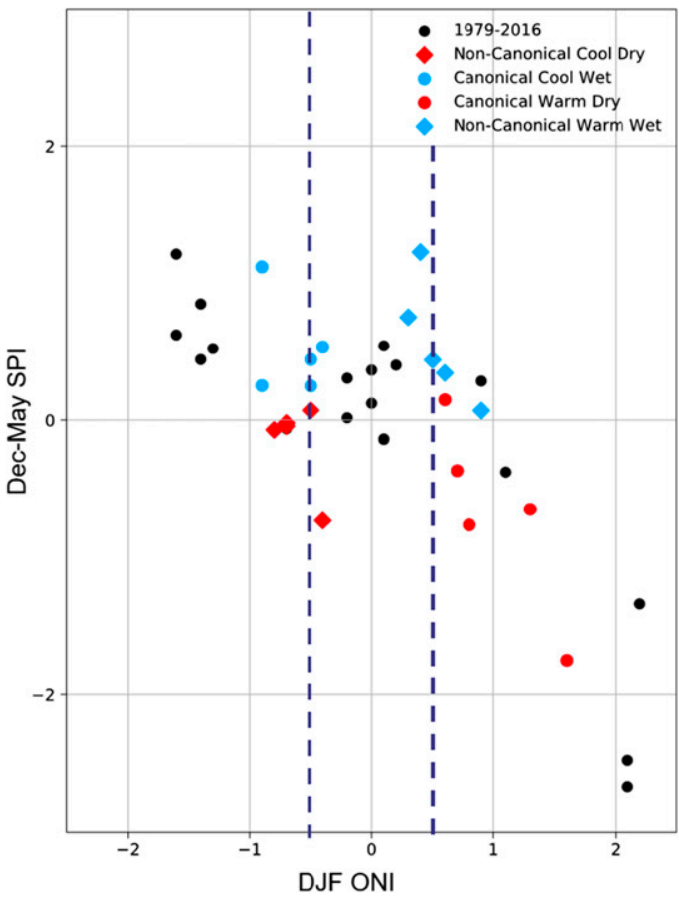

FIG. 3. Scatterplots of the dry season SPI (December-May) averaged for the (a) northern and (b) southern USAPI stations vs the ONI for the corresponding DJF season. Color markers represent years chosen for composite analysis. Diamond markers represent noncanonical years for which rainfall anomalies in the northern USAPIs are of opposite sign from what would be expected from the ONI conditions. Circular markers represent canonical years for which rainfall anomalies are as expected considering the corresponding ONI value. Vertical dashed lines indicate $\pm 0.5^{\circ} \mathrm{C}$ ONI values.

that the mean SPI for both categories is the same). For events in the cool dry and cool wet categories, this difference of mean SPI is even more significant, with a $p$ value of $1 \times 10^{-6}$.
For ONI values of $-1^{\circ} \mathrm{C}$ or less, both wet and dry rainfall conditions for the northern USAPIs occur, but in both cases, anomalies are not as pronounced as during years with weaker cool ONI anomalies. Years included

TABLE 1. Classification of all events selected for our composite analysis according to CPC operational methodology, Kug et al. (2009), and Murphy et al. (2014). WP stands for warm pool El Niño. Asterisks (**) represent years not included in the period considered in each study.

\begin{tabular}{|c|c|c|c|c|c|c|c|}
\hline \multicolumn{4}{|c|}{ Canonical cool wet } & \multicolumn{4}{|c|}{ Noncanonical warm wet } \\
\hline Year & CPC & Kug et al. (2009) & Murphy et al. (2014) & Year & $\mathrm{CPC}$ & Kug et al. (2009) & Murphy et al. (2014) \\
\hline 1985 & La Niña & La Niña & - & 1980 & El Niño & - & - \\
\hline 1986 & - & - & - & 1991 & - & WP El Niño & - \\
\hline 1996 & La Niña & - & - & 1995 & El Niño & WP El Niño & WP El Niño \\
\hline 1997 & - & - & - & 2004 & - & - & \\
\hline 2014 & - & $* *$ & - & 2015 & El Niño & $* *$ & $* *$ \\
\hline \multicolumn{4}{|c|}{ Noncanonical cool dry } & \multicolumn{4}{|c|}{ Canonical warm dry } \\
\hline Year & $\mathrm{CPC}$ & Kug et al. (2009) & Murphy et al. (2014) & Year & $\mathrm{CPC}$ & Kug et al. (2009) & Murphy et al. (2014) \\
\hline 1984 & La Niña & - & - & 1988 & El Niño & Mix El Niño & Mix El Niño \\
\hline 2001 & La Niña & La Niña & - & 1992 & El Niño & Mix El Niño & Mix El Niño \\
\hline 2006 & La Niña & La Niña & - & 2005 & El Niño & WP El Niño & WP El Niño \\
\hline 2009 & La Niña & $* *$ & - & 2007 & El Niño & $* *$ & WP El Niño \\
\hline 2013 & - & $* *$ & - & 2016 & El Niño & $* *$ & $* *$ \\
\hline
\end{tabular}


in this category are $1989,1999,2000,2008$, and 2011, all of which are considered La Niña years by CPC operational methodology, Murphy et al. (2014) and Kug et al. (2009), although Kug et al. (2009) leave out 2008 and 2011 due to the time period considered. Wet and dry strong La Niña events show low sample size (two events each) and comparatively weaker rainfall anomalies over the northern USAPIs. There is also an asymmetric behavior between strong El Niño events (which produce only dry conditions) and strong La Niña events. For these reasons, events with ONI values of less than $-1{ }^{\circ} \mathrm{C}$ and greater than $2^{\circ} \mathrm{C}$ are left out of this analysis.

It should also be noted that many of the years selected here that show the strong impacts over the northern USAPI region are not often studied because they are overlooked by most ENSO active phase selection criteria. In most cases, SST anomalies during these years do not meet magnitude or persistence criteria such as the CPC requirement for five consecutive seasons of ONI index being below -0.5 . Nonetheless, these events warrant a closer look given the severe drought conditions that occur in the USAPI region. The results in Fig. 3 can be reproduced using GPCP rainfall anomalies averaged over the northern USAPIs (the region defined by $10^{\circ}-15^{\circ} \mathrm{N}, 140^{\circ}-$ $170^{\circ} \mathrm{E}$ works best, but results remain consistent to reasonable changes in the area used to define rainfall anomalies).

\section{Distinct characteristics of the canonical and noncanonical responses to ENSO}

In this section, we contrast the composite climate anomalies between the canonical and noncanonical regimes. The highlighted differences between canonical and noncanonical events are summarized in Table 2. Composite rainfall patterns during canonical events (Fig. 4, top left and bottom right panels) show a familiar ENSO horseshoe shape. During warm dry events, wet anomalies occur over the central and eastern Pacific and dry anomalies over the western Pacific that extend northeast and southeast. During cool wet years, the opposite pattern occurs. The central Pacific rainfall anomalies observed during these events are confined to south of about $5^{\circ} \mathrm{N}$ and west of the date line and increase in latitudinal range to the east. The tropical western North Pacific (TWNP; $0^{\circ}-30^{\circ} \mathrm{N}, 120^{\circ} \mathrm{E}$ to the date line) is controlled by anticyclonic low-level wind anomalies that produce dry conditions in the region during warm dry years and cyclonic anomalies that produce wet conditions during the cool wet years. Looking at the same top left and bottom right panels of Figs. 5 and 6 we can see that canonical events also show the general features of SST and circulation anomalies characteristic of La Niña and El Niño events.
In contrast, the lower left and upper right panels of Fig. 4 show the same composites for the noncanonical cool dry and warm wet years. Because noncanonical cool dry events are of particular interest as they bring unexpected droughts to the USAPIs, we will focus on comparing the features of these events with those of their canonical cool wet counterparts, with comparisons for the warm events being opposite unless otherwise pointed out.

In the cool dry composite, the dry rainfall anomalies observed near the date line extend toward Micronesia, showing the strongest anomalies between about $7^{\circ}$ and $15^{\circ} \mathrm{N}$. This negative rainfall anomaly belt is not present in cool wet events. TWNP circulation during cool dry events shows well-defined anticyclonic anomalies, consistent with the observed rainfall anomalies in the area, while cool wet events show the TWNP dominated by cyclonic anomalies.

Canonical cool wet and noncanonical cool dry events differ significantly in their circulation patterns over a large portion of the Pacific basin, not only over the TWNP and subtropical Pacific (Fig. 5). Strong circulation anomalies in the TWNP during the December-May dry season are cyclonic for cool wet events and anticyclonic for cool dry events and in both cases show support from midlatitude circulation anomalies of the same sign. Over the eastern and southern Pacific basins, cool wet and cool dry events also show significant circulation differences. In the tropical South Pacific, noncanonical cool dry events show strong cyclonic circulation while the canonical cool dry composite shows weak anticyclonic anomalies over the entire region. In the tropical eastern Pacific $\left(140^{\circ} \mathrm{W}\right)$, cool wet events show a strong anticyclonic circulation pattern similar to what is observed during the decaying phase of La Niña events, whereas during cool dry events the eastern tropical Pacific shows weak cyclonic anomalies. The canonical warm dry composite shows one significant difference from the other composites in that the circulation anomalies over the central North Pacific and the TWNP are of opposite sign (see Table 2 for a summary of features).

The canonical and noncanonical cool events, while having similar DJF ONI values (all between $0^{\circ}$ and $-1^{\circ} \mathrm{C}$ ), show distinct equatorial and off-equatorial spatial SST anomaly patterns (Fig. 6). In the equatorial Pacific, cool wet years show strongest negative SST anomalies over the eastern Pacific from around $140^{\circ} \mathrm{W}$ extending toward the South American coast, with peak magnitude around $120^{\circ} \mathrm{W}$. Cool dry years show strongest negative anomalies to the east of $140^{\circ} \mathrm{W}$ and extending to the date line. In the TWNP, cool wet years show weak warm SST anomalies from the equator to about $20^{\circ} \mathrm{N}$, with cool 
TABLE 2. Summary table of the distinguishing features of canonical and noncanonical events.

\begin{tabular}{|c|c|c|c|}
\hline \multicolumn{2}{|c|}{ Canonical cool wet } & \multicolumn{2}{|c|}{ Noncanonical warm wet } \\
\hline \multirow[t]{6}{*}{ Dec-May dry season } & Negative ONI & Dec-May dry season & Positive ONI \\
\hline & Wet in the northern USAPIs & & Wet in the northern USAPIs \\
\hline & ENSO horseshoe rainfall pattern & & $\begin{array}{l}\text { Modified ENSO horseshoe rainfall } \\
\text { pattern }\end{array}$ \\
\hline & $\begin{array}{l}\text { Cyclonic circulation anomalies in the } \\
\text { western Pacific }\end{array}$ & & $\begin{array}{l}\text { Cyclonic circulation anomalies in the } \\
\text { western Pacific }\end{array}$ \\
\hline & $\begin{array}{l}\text { Maximum SST anomaly east of the } \\
\text { date line }\end{array}$ & & $\begin{array}{l}\text { Maximum SST anomaly near the date } \\
\text { line }\end{array}$ \\
\hline & $\begin{array}{l}\text { Cyclonic circulation anomalies in the } \\
\text { midlatitudes }\end{array}$ & & $\begin{array}{l}\text { Cyclonic circulation anomalies in the } \\
\text { midlatitudes }\end{array}$ \\
\hline \multirow{3}{*}{$\begin{array}{l}\text { Evolution of anoma- } \\
\text { lies from JJA and } \\
\text { SON to Dec-May }\end{array}$} & $\begin{array}{l}\text { Dry anomalies transition to wet } \\
\text { anomalies }\end{array}$ & $\begin{array}{l}\text { Evolution of anoma- } \\
\text { lies from JJA and }\end{array}$ & Wet anomalies persist \\
\hline & $\begin{array}{l}\text { Anticyclonic circulation anomalies in } \\
\text { the western Pacific transitions to } \\
\text { cyclonic }\end{array}$ & SON to Dec-May & $\begin{array}{l}\text { Cyclonic circulation anomalies in the } \\
\text { western Pacific persists through dry } \\
\text { season }\end{array}$ \\
\hline & $\begin{array}{l}\text { SSTs intensify in place over east } \\
\text { Pacific }\end{array}$ & & SSTs build from central Pacific to east \\
\hline \multicolumn{2}{|c|}{ Noncanonical cool dry } & \multicolumn{2}{|c|}{ Canonical warm dry } \\
\hline \multirow[t]{6}{*}{ Dec-May dry season } & Negative ONI & Dec-May dry season & Positive ONI \\
\hline & Dry in the northern USAPIs & & Dry in the northern USAPIs \\
\hline & $\begin{array}{l}\text { Modified ENSO horseshoe rainfall } \\
\text { pattern }\end{array}$ & & ENSO horseshoe rainfall pattern \\
\hline & $\begin{array}{l}\text { Anticyclonic circulation anomalies in } \\
\text { the western Pacific }\end{array}$ & & $\begin{array}{l}\text { Anticyclonic circulation anomalies in } \\
\text { the western Pacific }\end{array}$ \\
\hline & $\begin{array}{l}\text { Maximum SST anomaly near the date } \\
\text { line }\end{array}$ & & $\begin{array}{l}\text { Maximum SST anomaly east of the } \\
\text { date line }\end{array}$ \\
\hline & $\begin{array}{l}\text { Anticyclonic circulation anomalies in } \\
\text { the midlatitudes }\end{array}$ & & $\begin{array}{l}\text { Cyclonic circulation anomalies in the } \\
\text { midlatitudes }\end{array}$ \\
\hline \multirow{3}{*}{$\begin{array}{l}\text { Evolution of anomalies } \\
\text { from JJA and SON to } \\
\text { Dec-May }\end{array}$} & Dry anomalies persist & $\begin{array}{l}\text { Evolution of anoma- } \\
\text { lies from JJA and }\end{array}$ & $\begin{array}{l}\text { Wet anomalies transition to dry } \\
\text { anomalies }\end{array}$ \\
\hline & $\begin{array}{l}\text { Anticyclonic circulation anomalies in } \\
\text { the western Pacific persists through } \\
\text { dry season }\end{array}$ & SON to Dec-May & $\begin{array}{l}\text { Cyclonic circulation anomalies in the } \\
\text { western Pacific transitions to } \\
\text { anticyclonic }\end{array}$ \\
\hline & SSTs build from central Pacific to east & & $\begin{array}{l}\text { SSTs intensify in place over east } \\
\text { Pacific }\end{array}$ \\
\hline
\end{tabular}

anomalies to the north. During cool dry years, warm anomalies dominate the region. Equatorial low-level easterly winds in the cool wet events are confined east of the date line where the strongest zonal SST gradients are observed, while westerly wind anomalies that form on the southern side of the regional cyclonic circulation anomalies mentioned above dominate the western $\mathrm{Pa}$ cific. During cool dry events, easterly wind anomalies are only present west of $150^{\circ} \mathrm{W}$ and extend all the way to the Maritime Continent, forming the southern branch of the local anticyclonic circulation that characterizes these events. In the midlatitudes, the cool wet composites show a strong low pressure system and associated cyclonic circulation as well as cool and warm SST anomalies $\left(30^{\circ} \mathrm{N}\right.$ and date line and near the California coast, respectively). Midlatitude anomalies during cool dry events are opposite to those observed during cool wet events, with strong high pressure, anticyclonic circulation, and cool SST anomalies to the east and south and warm SST anomalies to the west.

Murphy et al. (2014) show results that suggest agreement with the observations made here. A composite of rainfall anomalies for warm pool El Niño events (their Fig. 5) suggests the anomalous rainfall band that extends from the central Pacific into the northern USAPI region that characterizes our noncanonical events. In their case, composite anomalies are not significantly different from zero. The warm pool El Niño events used for that composite are 1995, which is considered in this study to be a noncanonical warm wet year, and 2005 and 2007, which we consider canonical warm dry years. Similarly, in their composite for La Niña events (also their 


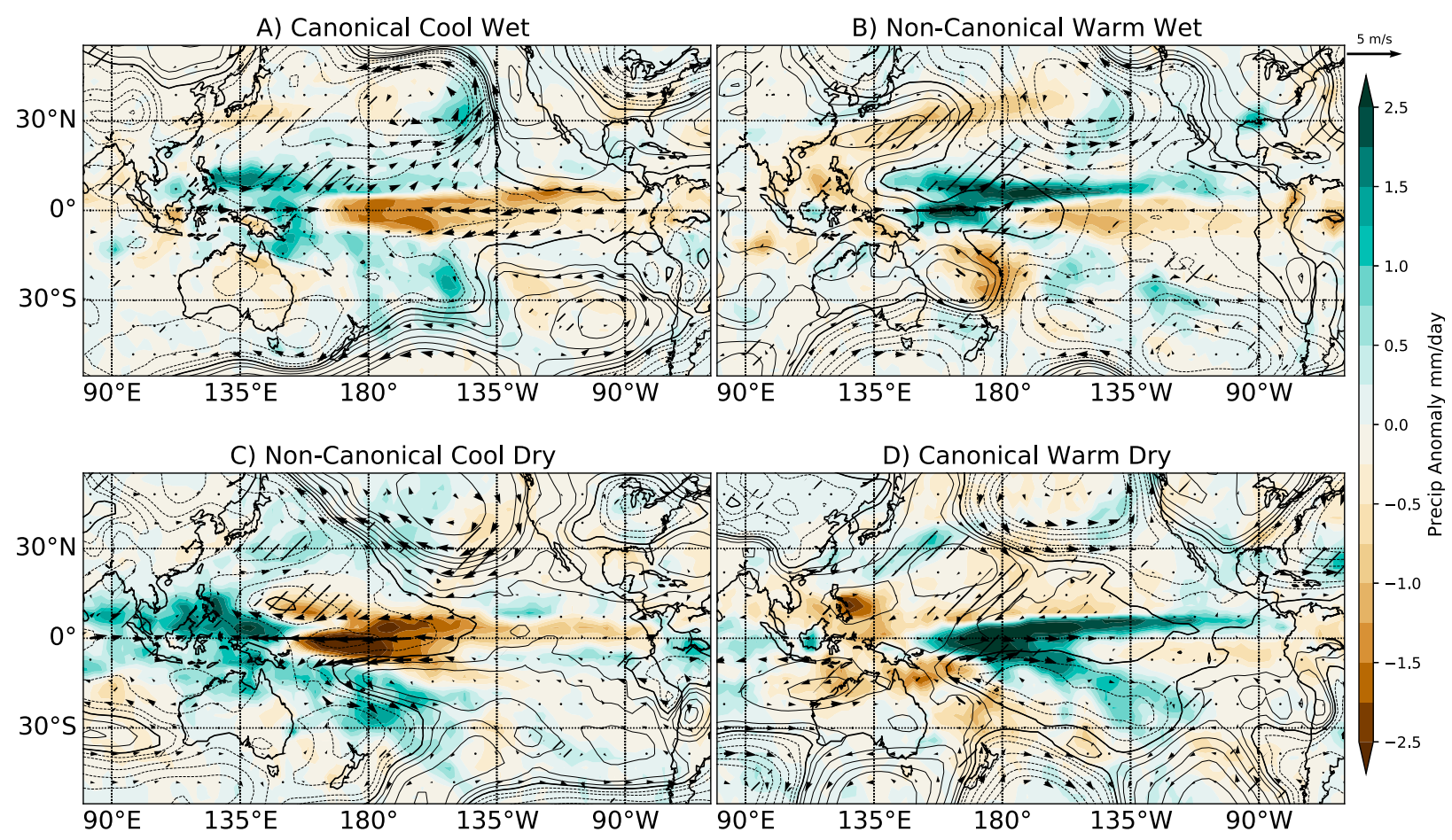

FIG. 4. Rainfall (shading), 850-hPa geopotential height (contours), and wind composites (vectors) for the canonical (a) cool wet and (d) warm dry and the noncanonical (c) cool dry and (b) warm wet years. Hashing represents areas where the difference in rainfall anomalies between composites of the same ONI character (e.g., cool wet vs cool dry) are significant at the $90 \%$ test level using a WilcoxonMann-Whitney rank-sum test.

Fig. 5), a band of anomalous rainfall extends from the central Pacific toward northern Micronesia, again failing statistical significance. The years used in their La Niña composite are 1989 and 2011 (considered wet La Niña events in our case), 1999 and 2008 (considered dry La Niña events), and 2000, which is left out of our analysis due to its near-normal rainfall anomalies over the northern USAPIs. The authors comment on this feature and suggest that in the case of warm pool El Niño events, these rainfall anomalies are linked to warm SST anomalies present over the TWNP. Our SST composites for warm wet events during the December-May season show warm SST anomalies confined near the date line with cool anomalies to the west. This SST dipole suggests that coupled ocean-atmosphere dynamics play a role in forcing local circulation anomalies and subsequent rainfall anomalies as suggested by Wang and Zhang (2002) rather than direct thermodynamic forcing. The anticyclonic circulation anomalies in the TWNP superimposed to the mean northeasterly winds increase (decrease) wind speed and associated evaporation/entrainment cooling, thus cooling (warming) the sea surface to the east (west) of the anticyclone. Conversely, SST cooling and dry advection to the east of the anticyclone can suppress convection. The resulting anomalous atmospheric cooling can excite descending atmospheric Rossby waves that in turn enhance the anticyclonic anomalies. Murphy et al. (2014) did not highlight the other features described here.

Using the SST-derived ENSO Modoki Index (EMI; Ashok et al. 2007), Weng et al. (2009) investigated the different impacts of ENSO flavors on winter (JanuaryMarch) climate in the Pacific Rim. They find that ENSO Modoki events show a rainfall and circulation pattern similar to our composite for rainfall anomalies during noncanonical warm wet events. The EMI is based on SST anomalies and does not sufficiently distinguish between our canonical and noncanonical events. For example; large negative EMI values are observed [see Fig. 1 in Weng et al. (2009)] for La Niña events of 1989, 1999, and 2000 that produce wet, dry, and near-neutral rainfall anomalies in the northern USAPIs. As we can see from the results of multiple studies (Kug et al. 2009; Weng et al. 2009; Murphy et al. 2014), SST-derived indices alone are unable to differentiate canonical and noncanonical events.

Noncanonical cool dry and warm wet composites show a near mirror image of each other, whereas this is not true for canonical cool wet and warm dry composites. A possible reason is that the canonical warm and cool events used for the composite study have different 
A) Canonical Cool Wet

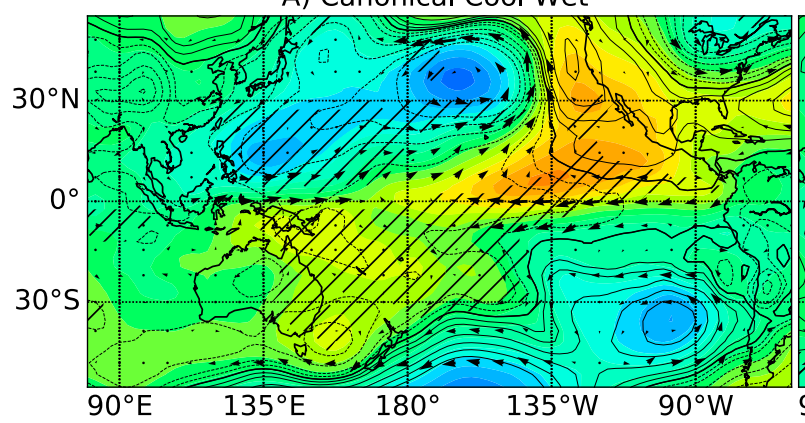

C) Non-Canonical Cool Dry

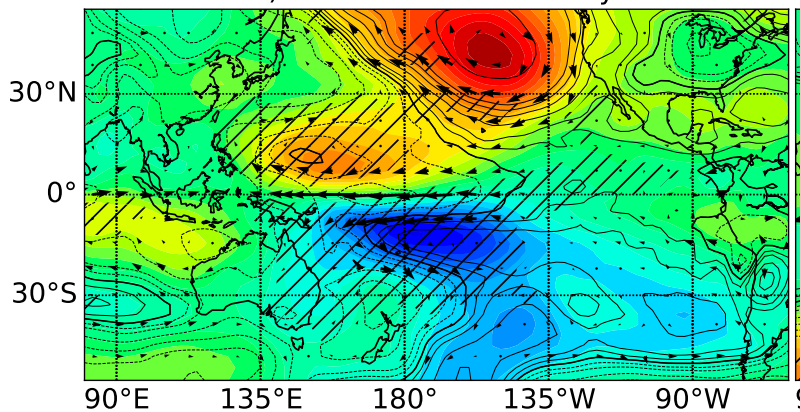

B) Non-Canonical Warm Wet

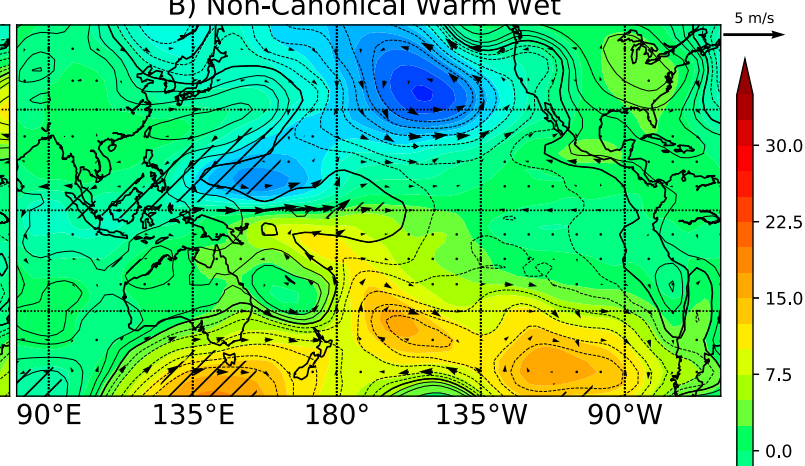

D) Canonical Warm Dry

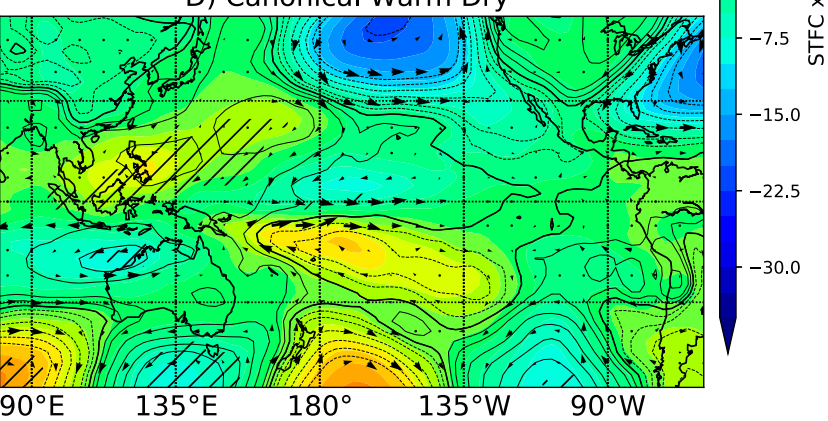

FIG. 5. As in Fig. 4, but for the streamfunction of the anomalous wind (shading), 850-hPa geopotential height (contours), and wind composites (vectors). Hashing represents $90 \%$ significance for streamfunction anomalies.

averaged intensity $\left(\sim+1.0^{\circ}\right.$ vs $\left.\sim-0.5^{\circ} \mathrm{C}\right)$ whereas the noncanonical warm and cool events used for the composite study have similar magnitude $\left(\sim+0.5^{\circ}\right.$ or $\left.-0.5^{\circ} \mathrm{C}\right)$. The asymmetry in the strength of the warming and cooling could cause an asymmetric response in the atmospheric circulation anomalies. Another possible reason is that the response of the precipitation and circulation at the northern islands seem to be highly nonlinear with respect to strong $\mathrm{El}$ Niño $\left(>1.0^{\circ} \mathrm{C}\right)$ and strong La Niña $\left(<-1.0^{\circ} \mathrm{C}\right)$ events as seen from the Fig. 3a. The sample size is relatively small (five for each group) and it is difficult to make a firm conclusion regarding the asymmetry in the response in general.

It is clear that during the December-May dry season, canonical and noncanonical warm and cool events exhibit distinctive atmospheric and oceanic anomalies that explain why their impacts on the northern USAPI region are so diverse. We will discuss in the following section how the evolution of these anomalies also differs between canonical and noncanonical events, making the difference between them even clearer.

\section{SST and atmospheric anomaly evolution during canonical and noncanonical events}

The evolution of the ONI generally is similar for canonical and noncanonical events. For canonical events, the ONI index leading up to the December-May dry season typifies ENSO with onset in the late spring to early summer and peak values by the end of the year (Fig. 7). The ONI evolution is similar for noncanonical warm wet events. For noncanonical cool dry events, however, the ONI seasonal evolution is less consistent. The onset happens later in the year, with ONI values during the preceding June-August (JJA) season showing a wide range. In the case of the 2013 event, ONI values are weak positive in 2012 as late as OctoberDecember, much later than any of the other years in this category.

Rainfall over the northern USAPIs is strongly modulated by the anomalous circulation over the TWNP. The evolution of TWNP anomalous circulation leading up to the December-May dry season differs remarkably between canonical and noncanonical events. Figure 8 shows the composite time series of northern USAPIs 6-month period SPI overlain on the TWNP streamfunction of anomalous winds averaged from the equator to $30^{\circ} \mathrm{N}$ and $120^{\circ} \mathrm{E}$ to the date line. During canonical events, we observe how rainfall anomalies over the northern USAPIs shift sign from the developing to the decaying stage of the events, in a manner opposite to the circulation anomalies over the TWNP. For warm dry events, this means a wetter than average June-November wet season and a drier than average December-May dry 
A) Canonical Cool Wet

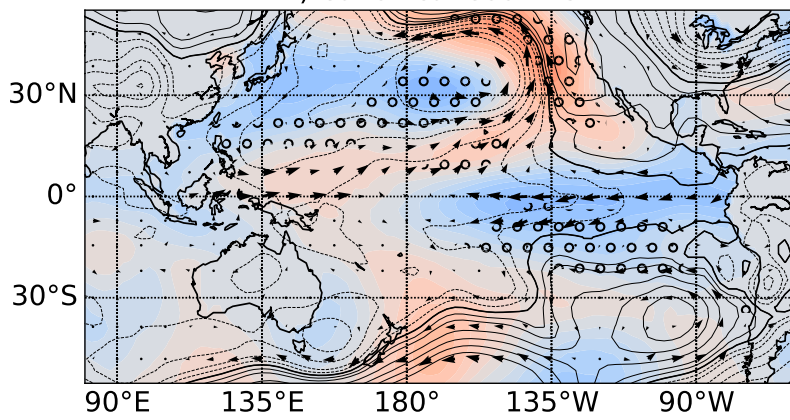

C) Non-Canonical Cool Dry
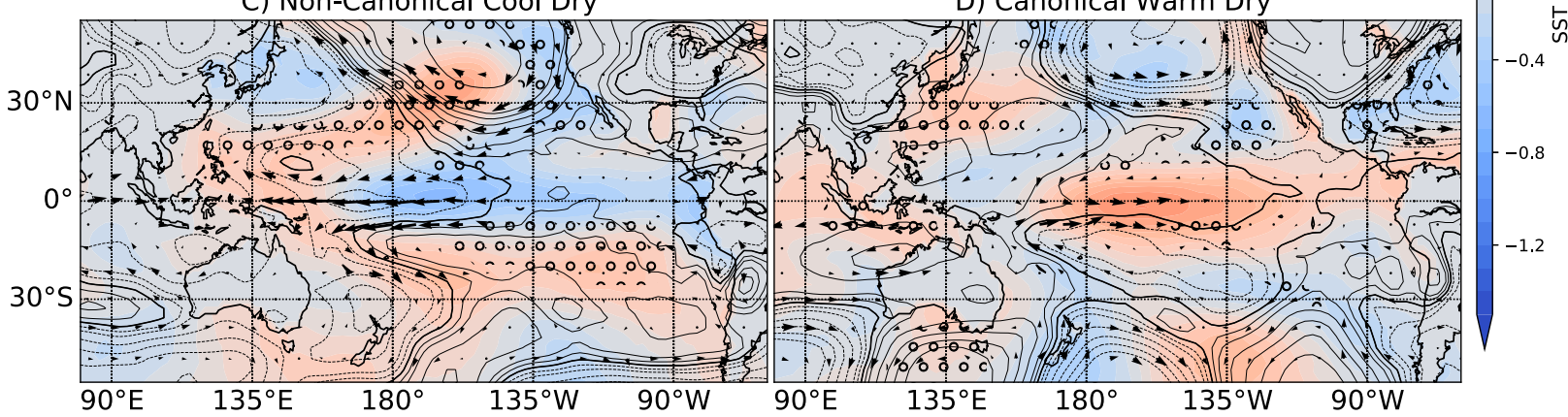

B) Non-Canonical Warm Wet

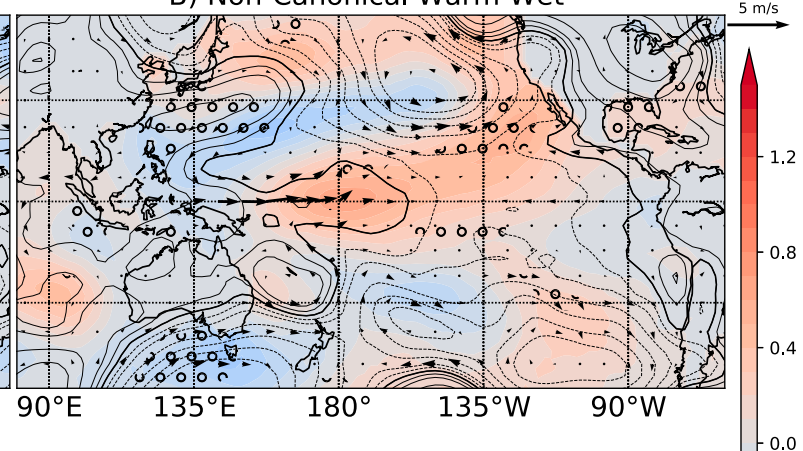

FIG. 6. As in Fig. 4, but for the SST anomaly (shading), 850-hPa geopotential height (contours), and wind composites (vectors). Circular hashing represents $90 \%$ significance for SST anomalies using a Student's $t$ test.

season. This transition in rainfall anomalies was described for El Niño events by Ropelewski and Halpert (1982) and is also seen in our cool wet composite with dry anomalies leading up to the December-May dry season sharply transitioning to wet anomalies. Noncanonical events, on the other hand, show persistence of rainfall anomalies from the June-November wet season through the December-May dry season that is linked to the persistent anomalous circulation anomalies over the TWNP. For cool dry events, this means that rainfall deficits during the December-May dry season are compounded, with deficient rainfall during the previous six months or more, making for severe drought impacts across the northern USAPIs during this type of event.

A progression of seasonal SST, 850-hPa winds, and geopotential height anomaly composites from MarchMay (MAM) on to the December-May dry season for each of our four categories (Fig. 9) emphasizes the different evolution of equatorial SST and TWNP circulation discussed previously. These composites also show differences in the evolution of off-equatorial SST anomalies and their link to circulation anomalies that are worth mentioning.

For cool dry events, the TWNP anticyclonic anomalies that linger until the dry season and produce dry season droughts are visible in the MAM composite and are linked to anticyclonic anomalies over the subtropical central Pacific. These subtropical circulation anomalies provide support for the localized central Pacific easterly wind anomalies observed in the MAM, JJA, and September-November (SON) seasons leading up to the December-May dry season in the cool dry composites. SST anomalies in these leading seasons are cool to the east and south of the tropical and subtropical anomalies, and warm to the north and west, suggesting that oceanatmosphere coupling could play an important role in the development and maintenance of these anomalies (Wang et al. 2000).

The anomalous SST features along the equator for canonical and noncanonical events also evolve differently from each other (Fig. 10). During canonical events, SST anomalies of the same sign as the DJF season ONI dominate the entire basin well ahead of the DecemberMay dry season, extending from about $160^{\circ} \mathrm{E}$. In the case of cool wet events the peak cool SST anomalies appear over the eastern Pacific off the South American coast. As the event evolves, these precursor SST anomalies intensify and extend from east to west peaking near $140^{\circ} \mathrm{W}\left(160^{\circ} \mathrm{W}\right.$ for warm dry events). Noncanonical events are characterized by an evolution of equatorial SST that is quite different. In the late spring and early summer of the developing year, an SST dipole pattern develops between the central and eastern Pacific. Cool dry events show warm SST anomalies off the South 

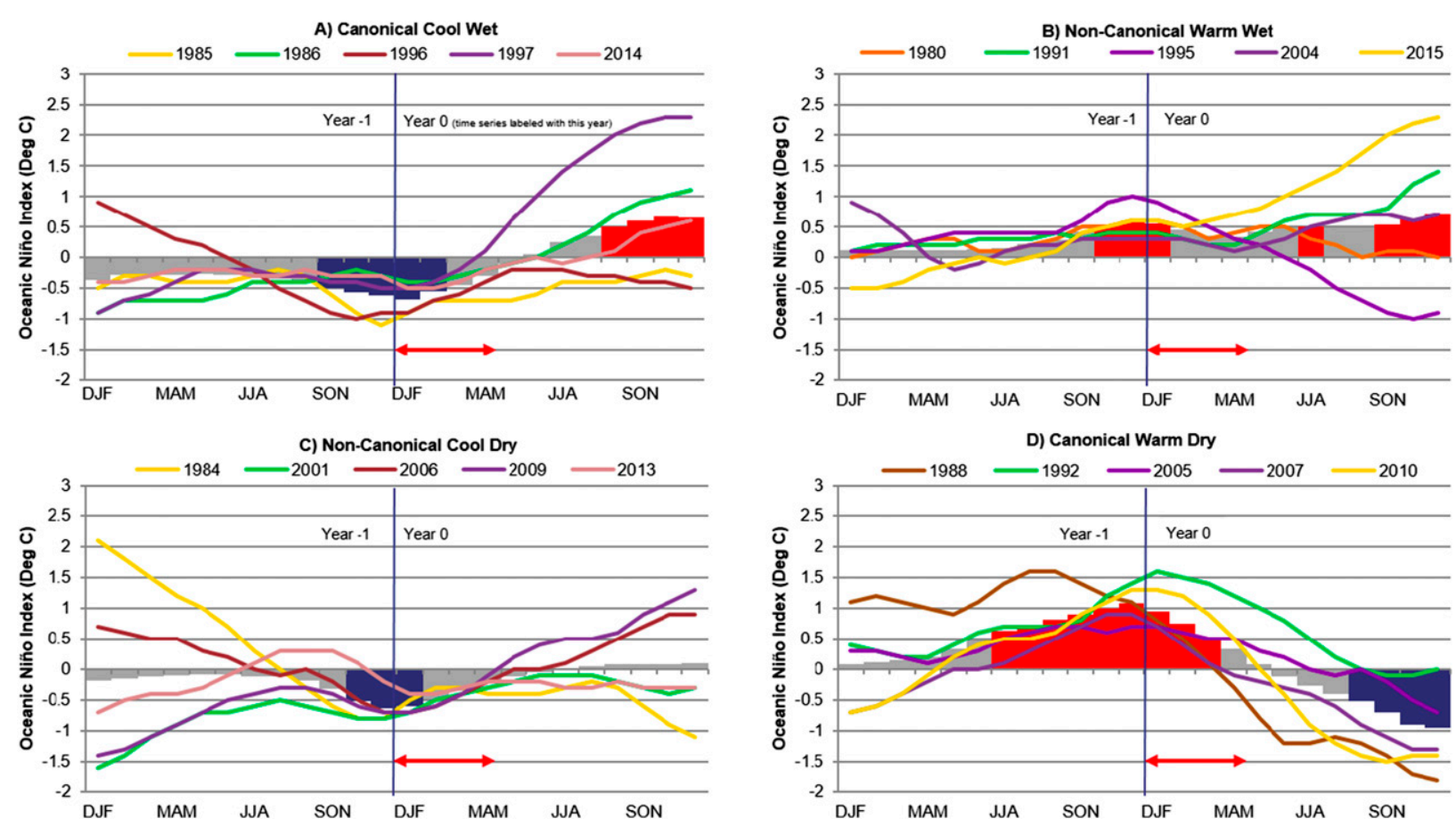

FIG. 7. Time series of the ONI in all composite years for each of the four categories. Bars represent the average of all events in each category, colored red where the average is greater than $0.5^{\circ} \mathrm{C}$ and blue where it is less than $-0.5^{\circ} \mathrm{C}$. The time series are labeled using the year 0. Red arrows depict the extent of the climatological December-May dry season.

American coast and cool SST anomalies over the central Pacific. These cool central Pacific anomalies then extend eastward covering most of the region east of the date line but with peak intensity strongly localized near the date line.

Hovmöller diagrams of monthly rainfall anomaly (shading) composites, averaged between $5^{\circ}$ and $15^{\circ} \mathrm{N}$, are presented along with streamfunctions of the anomalous winds averaged from $0^{\circ}$ to $30^{\circ} \mathrm{N}$ (contours) for each composite category (Fig. 11). Over the TWNP and the USAPI region $\left(130^{\circ} \mathrm{E}\right.$ to the date line), monthly rainfall shows the same behavior as described before using the time series of SPI, with canonical events showing rainfall anomalies that change sign before the onset to during the December-May dry season, and noncanonical events showing rainfall anomalies that persist. Canonical events are also characterized by an eastward propagation of rainfall and circulation anomalies from the TWNP toward the east. During cool wet events, negative rainfall and anticyclonic circulation anomalies first appear over the western Pacific as early as March and propagate eastward, being confined east of $160^{\circ} \mathrm{W}$ by the start of the December-May dry season. This progression is consistent with previous observations (Wang and Zhang 2002). This eastward propagation of rainfall and circulation anomalies is not observed in the noncanonical composites, for which homogeneous anomalies occupy most of the Pacific basin and persist from the developing year of the events through the dry season of the target year. It is seen that noncanonical events are characterized then by the persistence of anomalies not only over the TWNP but are associated with the suppression of tropical Pacific rainfall across a large part of the central Pacific from about $140^{\circ} \mathrm{E}$ to $120^{\circ} \mathrm{W}$.

The evolution of midlatitude SST and wind anomalies is also distinct for canonical and noncanonical events (see Fig. 9). For canonical cool dry events, we observe that the off-equatorial SST anomalies $\left(10^{\circ}-40^{\circ} \mathrm{N}\right.$, date line to $140^{\circ} \mathrm{W}$ ) are weaker than for the noncanonical cool wet cases during the MAM and JJA seasons (top four panels of Fig. 9). In noncanonical cool wet events, strong cool SST anomalies appear in the subtropical Pacific around $15^{\circ} \mathrm{N}$ and $140^{\circ} \mathrm{W}$ while for canonical cool wet events, SST anomalies in this region are warm. The winds in this region during the MAM and JJA seasons are also stronger during noncanonical cool dry than canonical cool wet events. Noncanonical cool dry events also show a connection between midlatitude and equatorial wind anomalies that is not seen in canonical events.

To understand the evolution of midlatitude anomalies and their possible role in supporting tropical anomalies 

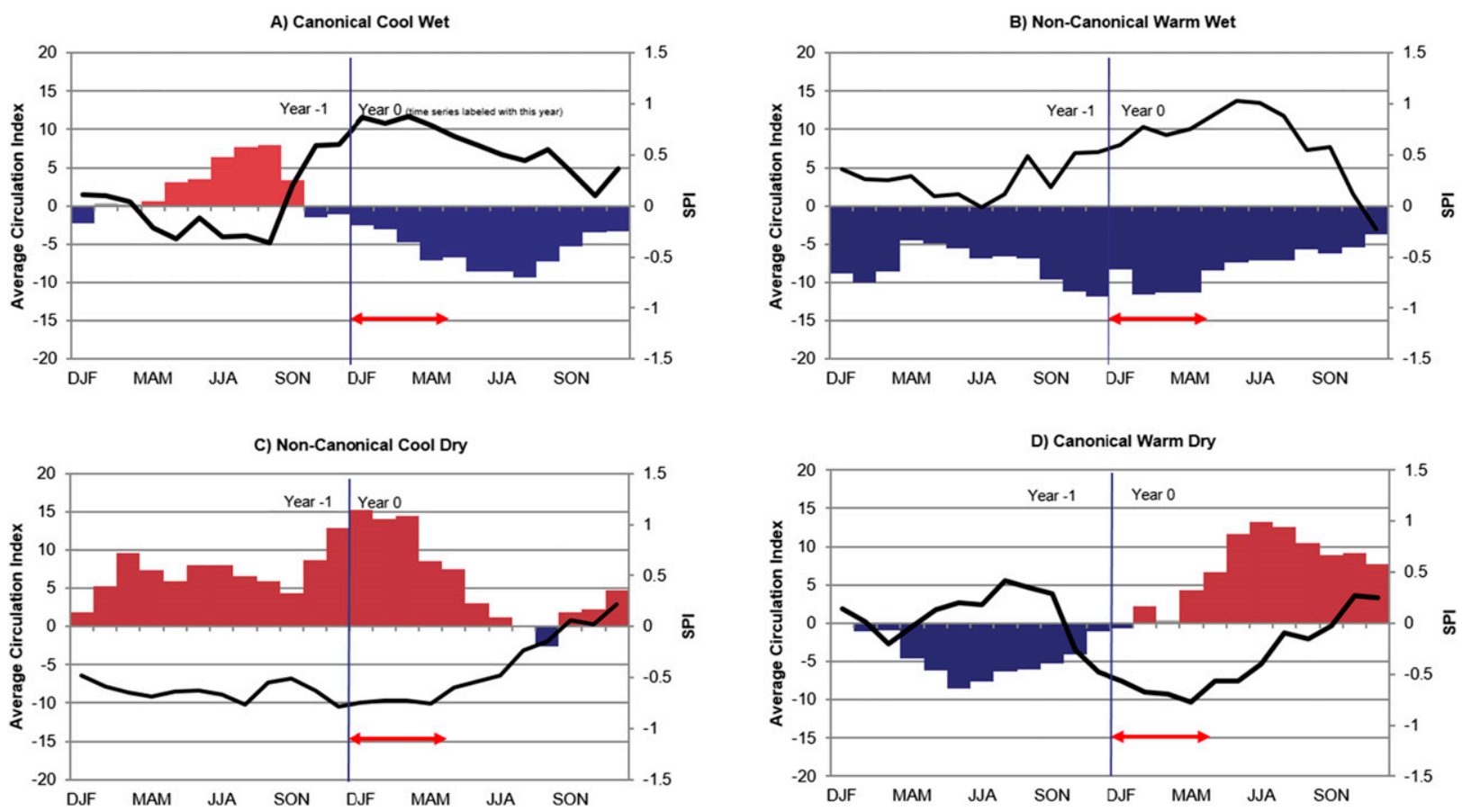

FIG. 8. Time series of the northern USAPIs SPI, composite-averaged for each of the four categories (black lines). The SPI in this figure is calculated for consecutive 6-month seasons. Bars represent the composite time series of the average streamfunction of anomalous winds over the tropical western Pacific. Red arrows depict the extent of the climatological December-May dry season.

during noncanonical events, Fig. 12 shows the evolution of SST anomalies between $20^{\circ}$ and $30^{\circ} \mathrm{N}$ (shading) and the evolution of monthly $850-\mathrm{hPa}$ geopotential height anomalies averaged from $30^{\circ}$ to $50^{\circ} \mathrm{N}$ (contours). Over the northern Pacific, noncanonical events show a strong relationship between geopotential height anomalies north of $30^{\circ} \mathrm{N}$ and SST anomalies south of $30^{\circ} \mathrm{N}$. Pressure anomalies over the northern Pacific and associated anomalous circulation produce strong SST anomalies. In the case of noncanonical cool dry events, high pressure anomalies to the North Pacific $\left(30^{\circ}-50^{\circ} \mathrm{N}\right)$ generate northeasterly anomalies to the south of the high pressure in the subtropical North Pacific $\left(20^{\circ}-30^{\circ} \mathrm{N}\right)$. These anomalous northeasterly winds superimposed to the climatological trades increase total wind speed and enhance evaporation/entrainment cooling and lead to cool SST anomalies to the east of the circulation anomalies $\left(135^{\circ} \mathrm{W}\right)$. Canonical cool wet events show behavior similar but opposite to that of cool dry events over the northern Pacific, with the cyclonic circulation anomaly over the extratropical North Pacific generating positive SST anomalies in the subtropical North Pacific. Canonical warm dry events show weak midlatitude anomalies both in geopotential height and SST, suggesting that warm dry events have less of a midlatitude influence than their canonical cool wet counterparts and noncanonical events.
The differences between peak dry season SST maxima coupled with their differences in evolution for canonical and noncanonical events described here are consistent with some previous ENSO diversity results. Modeling studies have shown that cold tongue and warm pool El Niño events have peak SST anomaly patterns that evolve from distinct initial condition patterns (Newman et al. 2011a,b). Precursor conditions in those studies were derived using observed SST, thermocline, and surface wind stress anomalies. The precursor conditions derived in those studies for cold tongue El Niño events are similar to the precursor season composite maps observed here for canonical warm dry events, with SST anomalies first appearing off the South American coast and extending west as the event matures (Newman et al. 2011b). Likewise, the precursor conditions derived for warm pool El Niño events are reminiscent of the composites produced here for noncanonical warm dry events. In these cases, an SST dipole is observed between the central and eastern Pacific (Newman et al. 2011b).

Observations have also been used to show that the seasonal evolution of SST anomalies differs for cold tongue and warm pool El Niño events (Kao and Yu 2009; Yeh et al. 2014). Cold tongue El Niño events feature SST anomalies that appear off the coast of South America during the spring and extend west as the event matures, just as is observed for canonical warm dry events (Figs. 9e-h). 

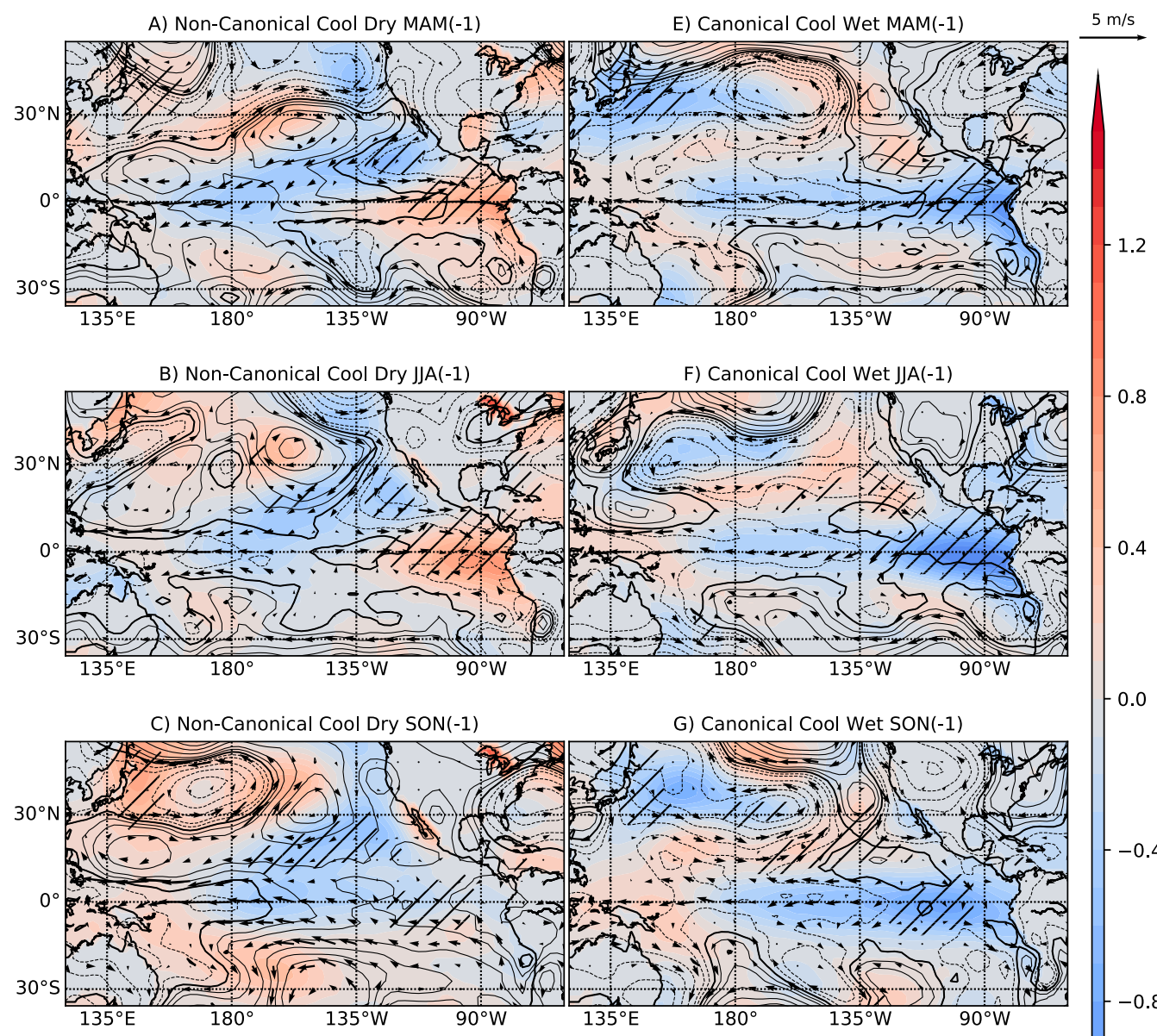

G) Canonical Cool Wet SON(-1)

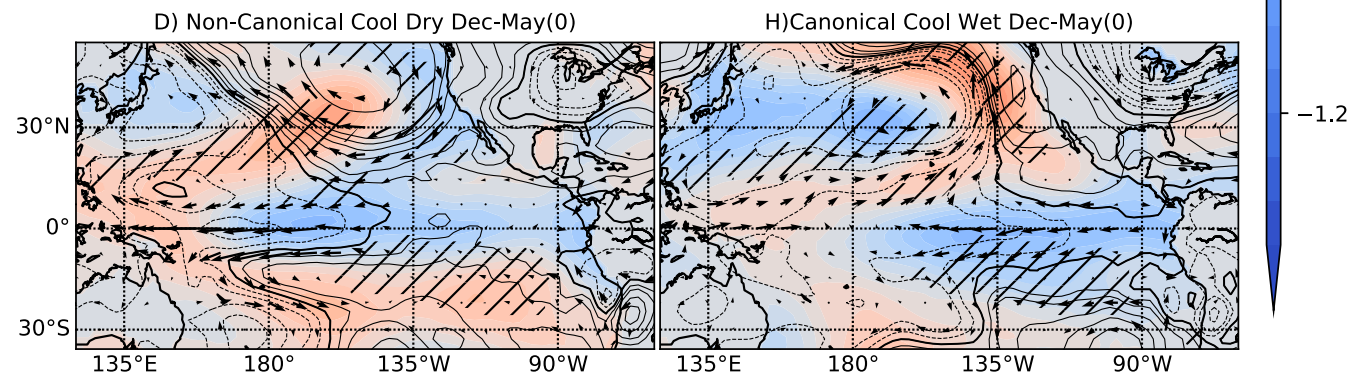

FIG. 9. Seasonal composites of SST (shading), 850-hPa geopotential height (contours), and wind (vectors) anomalies for the 3-month seasons (MAM, JJA, SON) leading up to the December-May dry season for (a)-(d) cool dry and (e)-(h) cool wet years. Hashing represents areas where the difference in SST anomalies between composites of the same ONI character (e.g., cool wet vs cool dry) are significant at the $90 \%$ test level using a Student's $t$ test.

On the other hand, similar to our noncanonical events, warm pool El Niño events show SST anomalies that extend from the eastern subtropical Pacific toward the central Pacific during spring and summer (Figs. 9a-d).

\section{Discussion}

A schematic diagram of anomaly differences for canonical and noncanonical events during the peak dry season from December to May illustrates the principal differences between the two categories (Fig. 13). We contend that canonical events represent the current understanding of ENSO events. Rainfall anomalies in canonical events are consistent with what is described as the ENSO "horseshoe" rainfall pattern over the Pacific with opposite anomalies in the central and eastern Pacific and the westernmost part of the basin. Canonical events have strongest SST anomalies east of the date 
sst Avg between -6 and 6

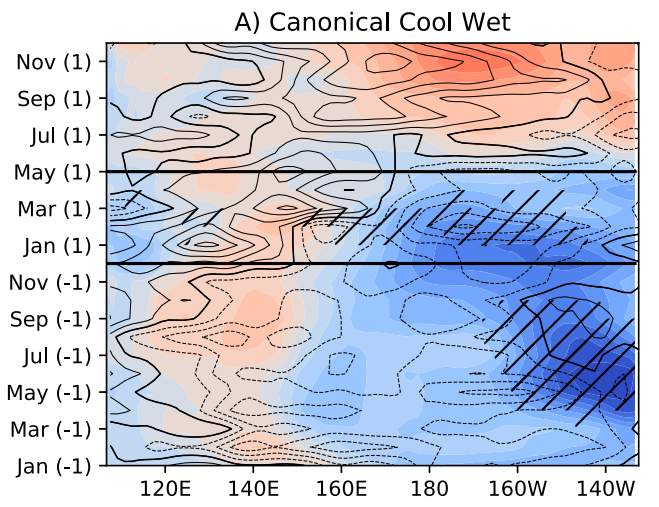

C) Non-Canonical Cool Dry

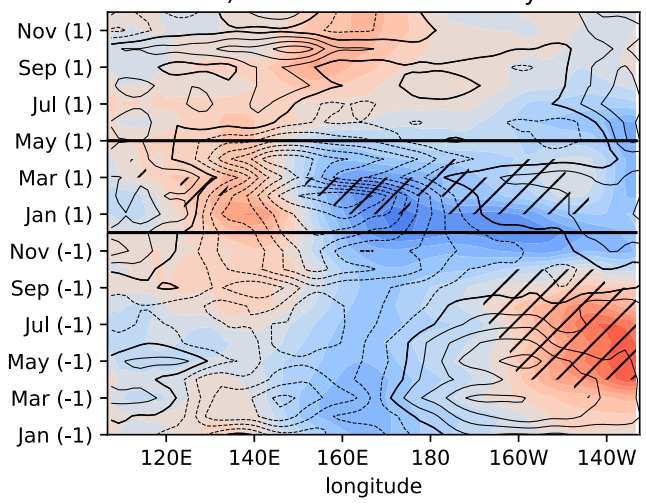

B) Non-Canonical Warm Wet
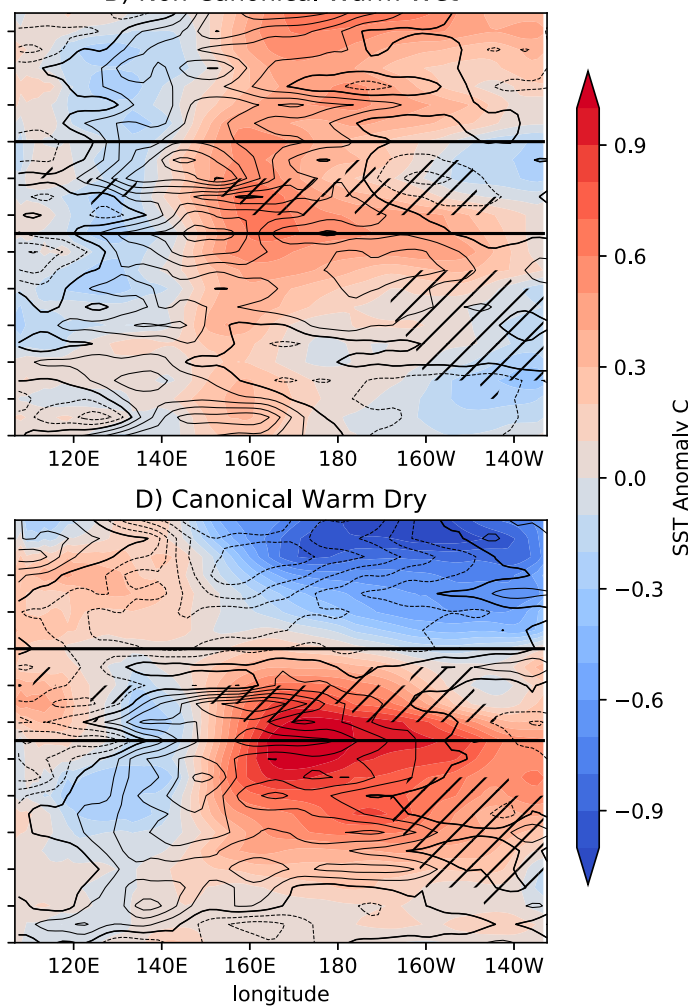

FIG. 10. Hovmöller diagrams of composite monthly SST (shading) and GODAS $20^{\circ} \mathrm{C}$ depth (contours) anomalies averaged from $6^{\circ} \mathrm{S}$ to $6^{\circ} \mathrm{N}$ for the four regimes. Black horizontal lines indicate the December-May northern USAPIs dry season. Hashing represents regions where the difference in rainfall anomalies between composites of the same ONI character (e.g., cool wet vs cool dry) are significant at the $90 \%$ test level using a Student's $t$ test.

line and opposite wind anomalies on either side of the date line.

Noncanonical events, on the other hand, show a modified horseshoe rainfall anomaly pattern characterized by a band of rainfall anomalies that extends from the central Pacific toward Micronesia. This rainfall band is driven by western Pacific circulation anomalies of opposite sign than those observed for canonical events of similar ONI sign and intensity. Noncanonical events have the strongest SST anomalies over the central Pacific near the date line, with weak SST anomalies to the east and opposite signed anomalies to the west as well as having the strongest equatorial wind anomalies in the western Pacific.

The difference in the evolution of anomalies leading up to the December-May dry season suggests different physical mechanisms behind the canonical and noncanonical modes of variability. During canonical cool wet events, for example, anticyclonic circulation anomalies over the TWNP are observed in the six months before the December-May dry season. The southern branch of this anticyclonic pattern is the equatorial anomalous easterly winds whose fluctuation can trigger consecutive upwelling Kelvin waves that propagate eastward and intensify the cooling in the eastern Pacific. As eastern Pacific cooling intensifies, the locations of the enhanced westward SST gradients and associated equatorial easterly anomaly and convective anomaly as well as the associated off-equatorial anticyclonic circulation (as a Gill-type response) all migrate eastward (Figs. 4-6). The original anticyclonic anomalies are then located in the eastern Pacific; as a result, anomalous southwesterlies develop to its west, which reduces the mean trade winds and evaporation/entrainment cooling, causing positive SST anomalies in the western Pacific, forming a tilted band of complementary warming extending from the equatorial western Pacific to tropical central North Pacific (Fig. 6). This complementary warming and associated enhanced precipitation can further generate cyclonic anomalies over the Philippine Sea. The positive feedback between the Philippine Sea cyclonic anomaly and the warm SST anomaly to its east 

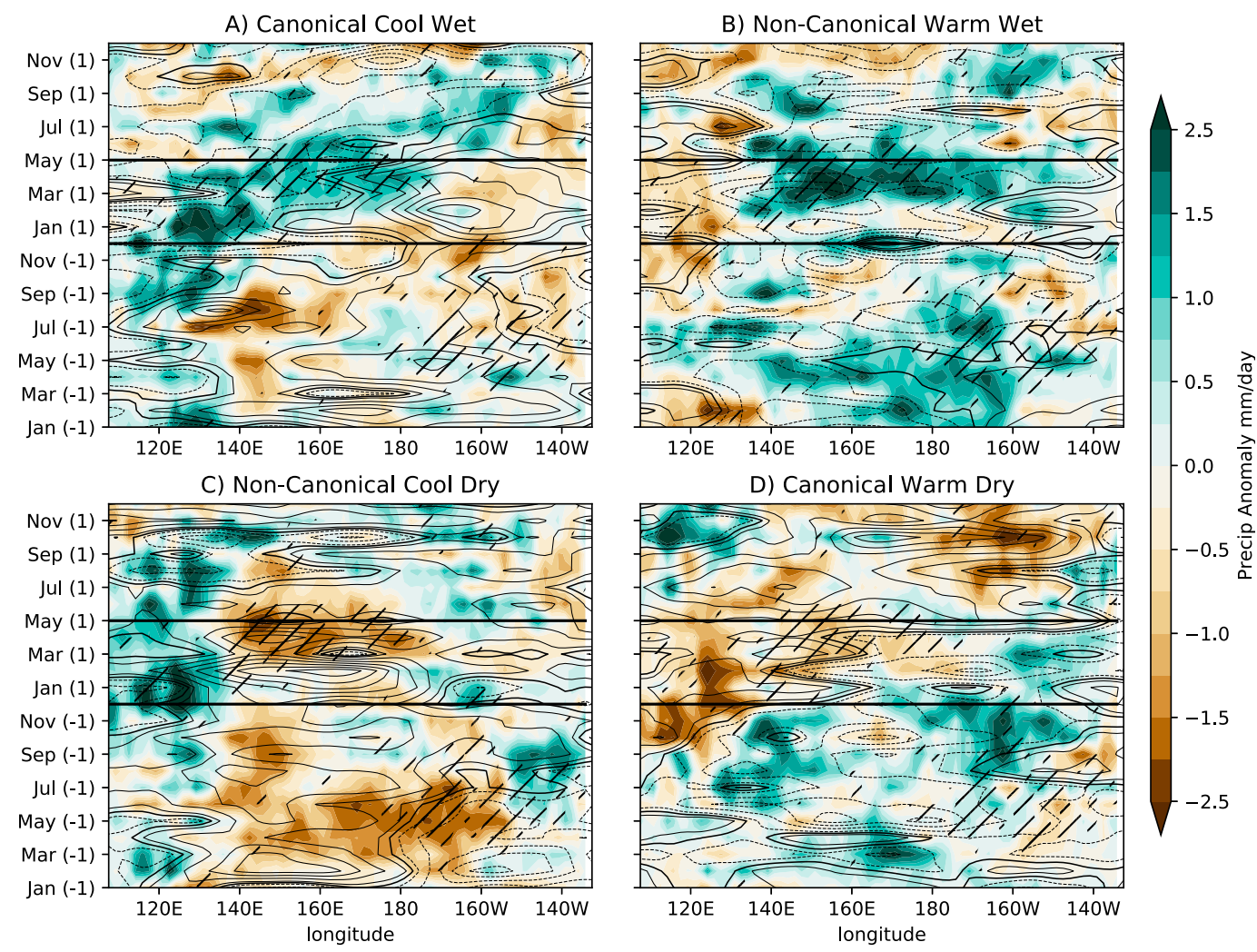

FIG. 11. Hovmöller diagrams of composite monthly rainfall anomalies averaged from $5^{\circ}$ to $15^{\circ} \mathrm{N}$ (shading) and streamfunction of the anomalous winds averaged between $0^{\circ}$ and $30^{\circ} \mathrm{N}$ (contours) for the four regimes. Contours range between $\pm 30 \times 10^{5}$ in intervals of $3 \times 10^{5} \mathrm{~m}^{2} \mathrm{~s}^{-1}$. Black horizontal lines indicate the dry season. Hashing represents regions where the difference in rainfall anomalies between composites of the same ONI character (e.g., cool wet vs cool dry) are significant at the $90 \%$ test level using a Wilcoxon-Mann-Whitney rank-sum test.

can maintain the cyclonic anomalies (Wang et al. 2000; Wang and Zhang 2002), causing wetter than normal climate in the northern USAPIs. Canonical warm dry events show a similar progression of events with opposite sign.

Noncanonical cool dry events also show anticyclonic circulation anomalies over the TWNP in the months leading up to the December-May dry season, but these fail to trigger the development of more intense SST anomalies over the eastern Pacific. Anticyclonic circulation anomalies hence do not migrate eastward during these events and remain anchored over the TWNP with regional air-sea interaction likely playing a significant role in their maintenance. The persistent anticyclonic circulation over Micronesia and resulting persistent dry rainfall anomalies in the northern USAPI region then lead to the severe droughts observed during these types of events. Because noncanonical warm wet events show similar but opposite dry season anomalies as well as anomaly evolution, it seems appropriate to think of these events as the two sides of a single mode of variability.
The separation made between canonical and noncanonical events in this study is valuable for drought forecasting in the northern USAPI region. The distinction may not prove as useful for other regions impacted by ENSO or for the ENSO community at large. As pointed out in the previous sections, however, many of the most distinct features of noncanonical events have not been analyzed in detail. Nonetheless, some of the results presented here are consistent with previous findings from ENSO diversity studies. Canonical warm dry events show peak dry season anomalies and seasonal evolution of those anomalies consistent with some previous observation and modeling results found for cold tongue El Niño events. Similarly, our results for noncanonical events show some overlap with previous results obtained for warm pool El Niño events (see Capotondi et al. 2015; Newman et al. 2011a,b; Kao and Yu 2009; Yeh et al. 2014; Wang and Zhang 2002; Ropelewski and Halpert 1987; Stuecker et al. 2015). It may be that noncanonical events can be incorporated 
sst Avg between 20 and 30

A) Canonical Cool Wet

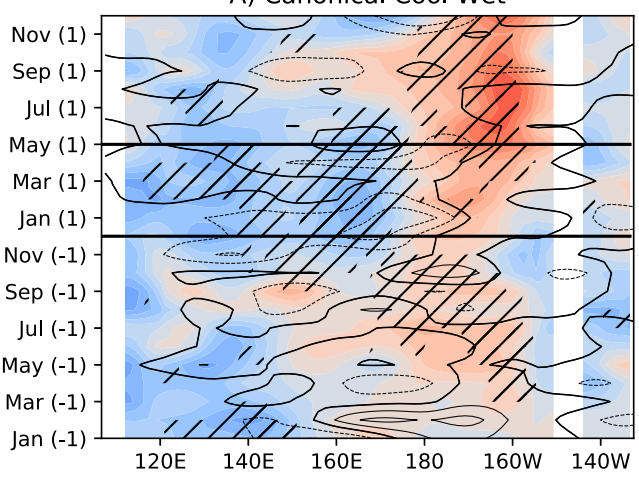

C) Non-Canonical Cool Dry

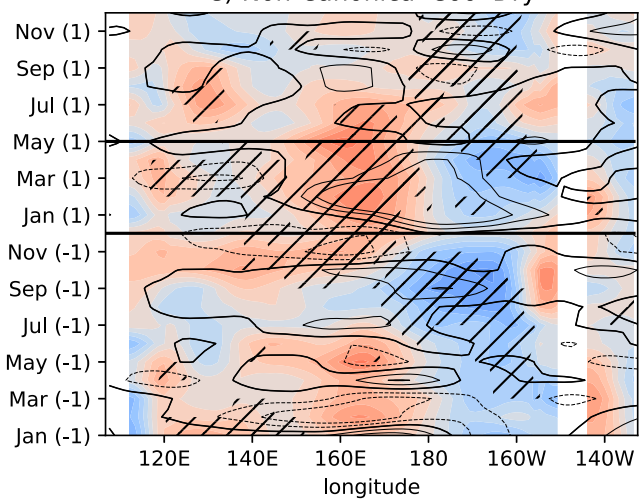

B) Non-Canonical Warm Wet

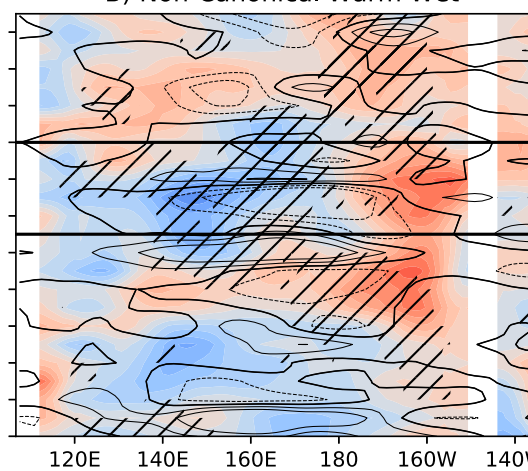

D) Canonical Warm Dry

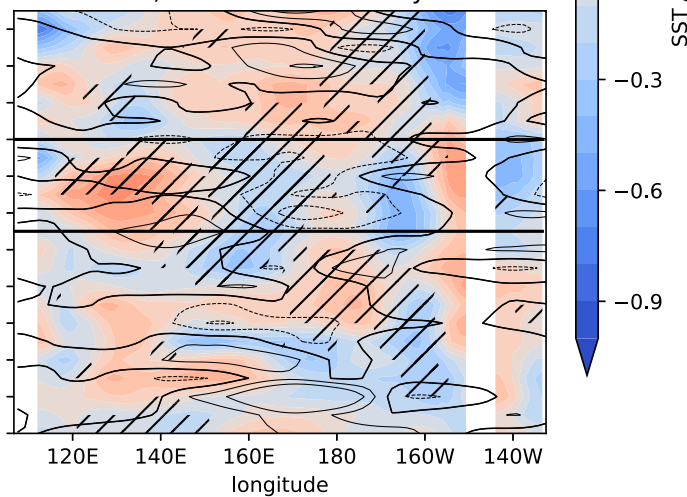

0.9

0.6

$-0.3$

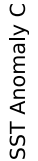

FIG. 12. As in Fig. 11, but for monthly SST anomalies averaged from $20^{\circ}$ to $30^{\circ} \mathrm{N}$ (shading) and 850 -hPa geopotential height anomalies from $30^{\circ}$ to $50^{\circ} \mathrm{N}$ (contours). Hashing represents $90 \%$ significance test for SST anomalies using a Student's $t$ test.

into the larger landscape as being thought to represent the most extreme of warm pool ENSO events. In these extreme warm pool events, SST anomalies are so strongly constrained to the central Pacific that the evolution of TWNP circulation, and subsequently, rainfall, is dramatically different from that of events in which SST anomalies peak farther east. This is not unlike the fact that the most extreme cold tongue El Niño events, such as 1982/83, 1997/98, and 2015/16, share their own set of distinguishing features that separate them from events with peak SST anomalies farther to the west.

While our methodology and analysis significantly improved our understanding of the causes of droughts across the USAPIs, it does not cover all possible disaster-level droughts observed in the recent record. During 2016/17 an extremely localized disaster-level drought affected the northern part of the Federated States of Micronesia. Like our noncanonical cool dry events, this drought coincided with cool ONI conditions and affected the same region as other noncanonical cool dry events. Nonetheless, because dry conditions were strongly localized, our proxy stations of Kwajalein and
Guam did not register dry conditions, and thus 2017 is not classified as a cool dry event according to our methodology. A review of PEAC Center forecast materials for early 2017 reveals that the SST anomalies during December-January were not as strongly constrained to the central Pacific as observed during noncanonical cool dry events. Strong SST anomalies in the central Pacific develop by January-February but are almost gone by March-April. The low-level circulation during these months also does not appear to organize in the same clear way as observed during noncanonical cool dry events. This suggests that event short-lived SST anomalies in the central Pacific can induce strong, localized rainfall anomalies.

The event selection methodology used in this work provides a framework to examine the causes of dry season rainfall anomalies in the northern USAPI region outside traditional ENSO events. It has the virtue of highlighting years that do not show the expected impacts of ENSO over the region, such as 1995 with wetter than normal conditions over the northern USAPIs, or that would be overlooked by selection criteria based only on 


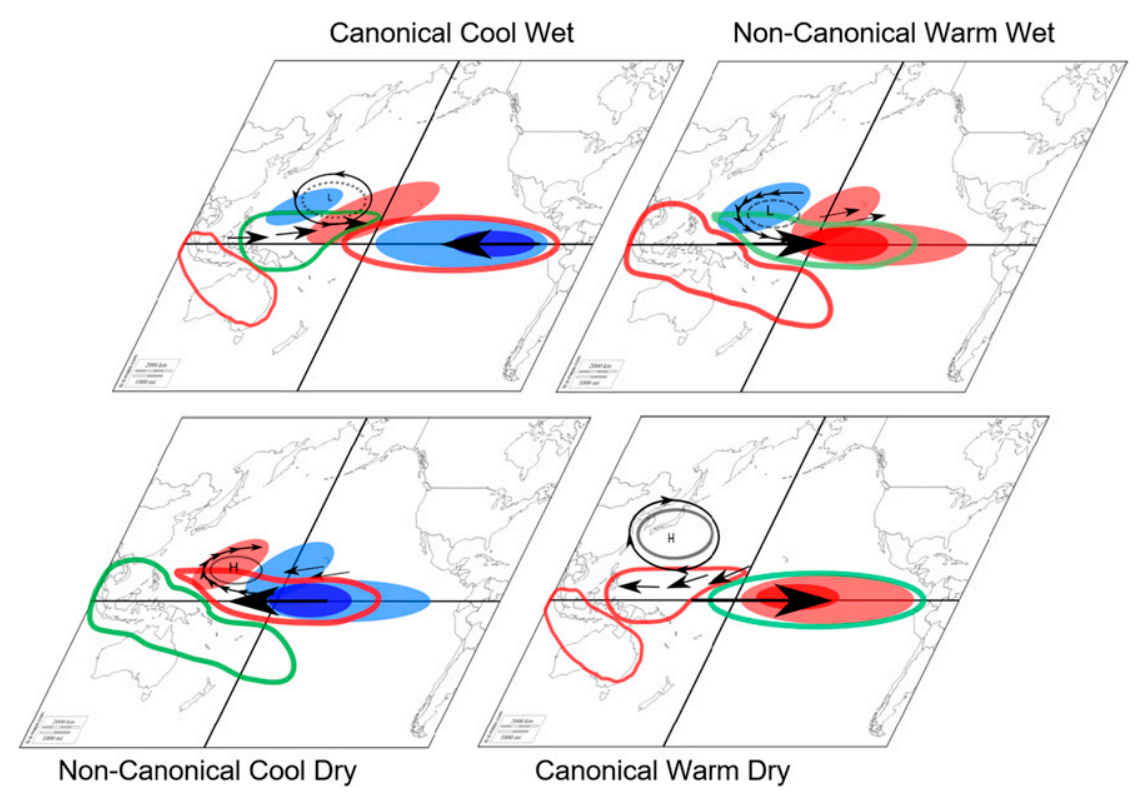

FIG. 13. Schematic diagram of relevant December-May SST and atmospheric circulation anomalies that lead to different rainfall conditions over the USAPI region. Rainfall anomalies are represented as contours, with red for dry and green for wet anomalies; SST anomalies are represented as filled shapes and geopotential height anomalies as gray contours, solid for positive and dashed for negative. Winds are represented as black arrows with equatorial wind anomalies represented in bold black arrows.

SST, such as 2013, whose drought impacts were described in the introduction.

The analysis is limited by the small sample size of five members per composite category out of 36 years. This makes the detailed analysis of the finer differences in our composites contentious, but the most important features highlighted in our work are considered statistically significant. While the analysis shown here is suggestive of differences in physical mechanisms acting during canonical and noncanonical events, future work should be aimed at verifying the physical mechanisms proposed here.

\section{Conclusions}

While the southern USAPI region tends to exhibit rainfall variability that is tied to ENSO, for the northern USAPIs, although many years conformed to the expected negative relationship between rainfall and ENSO with positive ONI value producing dry conditions and vice versa, a similar number of years appeared to have a positive relationship between rainfall and ENSO. Years with a negative relationship between rainfall and ENSO are grouped into two categories, cool wet and warm dry, and together these categories are described here as having the "canonical" response or simply as being canonical years. Conversely, years with a positive relationship between rainfall and ENSO are grouped into cool dry and warm wet years and these categories together are described as noncanonical.

We find that the 2013 disaster level drought was not an isolated event, finding as four previous years in the 1979-2016 record exhibit dry conditions in the northern USAPIs that coincide with cool Pacific SST conditions. For example, according to reports collected in the PEAC Pacific ENSO Update, persistent noncanonical cool dry conditions occurred in 2006 in Guam, which led to a longer than normal wildfire season, resulting in evacuations, and very low levels in the Fena reservoir, which provides water to about $20 \%$ for the population. In Majuro, water rationing was mandated during February 2006 and encouraged through the following months. Similarly, in 2009 persistent dry conditions in the northern RMI required the delivery of drinking water to Utirik in late April and the issuing of special weather statements for the RMI by the Guam National Weather Service Forecast Office. Both 2006 and 2009 are classified as La Niña events by most recent CPC methodology, but we contend that they differ from other La Niña events because of their noncanonical rainfall behavior.

Composites of SST, 850-hPa winds, geopotential height, and precipitation were produced for the canonical warm dry and cool wet as well as the noncanonical warm wet and cool dry years. Composite characteristics during the peak dry season as well as the evolution of relevant anomaly 
fields show clear differences for canonical and noncanonical events, suggesting that the variability mechanisms that produce events in each category may be different.

During the December-May dry season, canonical and noncanonical events show opposite circulation anomalies over the tropical western North Pacific (TWNP; $0^{\circ}-$ $30^{\circ} \mathrm{N}, 120^{\circ} \mathrm{E}$ to the date line). Canonical cool wet events show cyclonic circulation anomalies over the TWNP and rainfall anomaly patterns consistent with what is commonly described as a La Niña "horseshoe" pattern, with wet anomalies to the west and dry anomalies over the central and eastern Pacific. Noncanonical cool dry events, on the other hand, have anticyclonic anomalies over the TWNP. This produces a dry anomaly band that modifies the horseshoe pattern and extends dry conditions from the central and eastern Pacific into the northern USAPIs. SST anomalies are also different, with noncanonical events characterized by strongest anomalies constrained to a narrow region of the Pacific near the date line and canonical events showing anomalies farther east. These differences are also true when comparing canonical warm dry and noncanonical warm wet events, with circulation and rainfall anomalies being opposite.

Equally important as their differences during the dry season is the distinct ways in which canonical and noncanonical events evolve leading up to the dry season. Canonical events are characterized by a transition of circulation anomalies over the TWNP from the onset of the events in the spring to the December-May dry season, while noncanonical events are characterized by the persistence of these anomalies. For canonical cool wet events, we observe that anticyclonic circulation anomalies are present in the western part of the basin in early spring and summer and transition to cyclonic anomalies as December-May approaches. Conversely, in noncanonical cool dry events, TWNP anticyclonic anomalies are present as early as the preceding MAM season and linger through December-May. This makes long-term persistent droughts brought on by noncanonical cool dry events a concern for the USAPIs. This difference in evolution is also reflected in SST anomalies, with east to west propagation observed for canonical events compared to in situ development over the date line observed for noncanonical events.

It is proposed here that the division of events into canonical and noncanonical types can be integrated into larger ENSO paradigms. It is thought that noncanonical events are the most extreme representatives of the warm pool type of ENSO events, with peak SST anomalies strongly restricted to the central Pacific. Events with peak SST anomalies farther east constitute the canonical category. Because of this difference in SST anomaly location, canonical and noncanonical events show a distinct seasonal evolution and set of impacts.
Previously published work links the rainfall variability on USAPIs exclusively to ENSO with dry conditions throughout the region occurring during El Niño and wet conditions occurring during La Niña. This understanding leaves little guidance for forecasting during neutral or weak ENSO conditions and does not provide context for years during which rainfall impacts are not expected based on ENSO conditions. Our work proposes that differences in SST and circulation anomaly patterns during years that do not meet general criteria to be classified as ENSO events can produce distinct and significant changes in local precipitation patterns and produce severe drought impacts in some regions of the USAPIs. We hope that these new insights will lead to better tools for forecasting these types of dry events, which in turn will improve the ability to deliver timely and accurate climate forecasts to USAPI communities.

Acknowledgments. This project was funded by cooperative agreement NA17RJ1230 between the Joint Institute for Marine and Atmospheric Research (JIMAR) and the National Oceanic and Atmospheric Administration (NOAA). The views expressed herein do not necessarily reflect the views of NOAA or any of its subdivisions. We thank the reviewers for their thoughtful and through review of this manuscript and in particular Reviewer \#2 for supplying additional rainfall data for Wotje. Bin Wang acknowledges the support from National Science Foundation (Climate Dynamics Division) Award AGS1540783. This is SOEST publication 10364, IPRC publication 1321, and ESMC publication 215.

\section{REFERENCES}

Adler, R. F., and Coauthors, 2003: The version-2 Global Precipitation Climatology Project (GPCP) monthly precipitation analysis (1979-present). J. Hydrometeor., 4, 1147-1167, https:// doi.org/10.1175/1525-7541(2003)004<1147:TVGPCP >2.0.CO;2.

Arthur, D., and S. Vassilvitskii, 2007: k-means ++: The advantages of careful seeding. Proc. 18th Annual ACM-SIAM Symp. on Discrete Algorithms, New Orleans, LA, Society for Industrial and Applied Mathematics, 1027-1035.

Ashok, K., S. K. Behera, S. A. Rao, H. Weng, and T. Yamagata, 2007: El Niño Modoki and its possible teleconnection. J. Geophys. Res., 112, C11007, https://doi.org/10.1029/2006JC003798.

Bjerknes, J., 1966: A possible response of the atmospheric Hadley circulation to equatorial anomalies of ocean temperature. Tellus, 18, 820-829, https://doi.org/10.3402/tellusa.v18i4.9712. 1969: Atmospheric teleconnections from the equatorial Pacific. Mon. Wea. Rev., 97, 163-172, https://doi.org/10.1175/ 1520-0493(1969)097<0163:ATFTEP >2.3.CO;2.

Cai, W., and T. Cowan, 2009: La Niña Modoki impacts Australia autumn rainfall variability. Geophys. Res. Lett., 36, L12805, https://doi.org/10.1029/2009GL037885.

Capotondi, A., and Coauthors, 2015: Understanding ENSO diversity. Bull. Amer. Meteor. Soc., 96, 921-938, https://doi.org/ 10.1175/BAMS-D-13-00117.1. 
Chowdhury, M. R., P.-S. Chu, and T. Schroeder, 2007: ENSO and seasonal sea level variability-A diagnostic discussion for the U.S.-Affiliated Pacific Islands. Theor. Appl. Climatol., 88, 213 224, https://doi.org/10.1007/s00704-006-0245-5.

Collins, D., and Coauthors, 2011: Observed climate variability and trends. Climate change in the Pacific: Scientific assessment and new research, Australian Bureau of Meteorology Rep., 51-77.

Davies, D. L., and D. W. Bouldin, 1979: A cluster separation measure. IEEE Trans. Pattern Anal. Mach. Intell., 1, 224-227, https://doi.org/10.1109/TPAMI.1979.4766909.

Huang, B., and Coauthors, 2015: Extended Reconstructed Sea Surface Temperature version 4 (ERSST.v4): Part I. Upgrades and intercomparisons. J. Climate, 28, 911-930, https://doi.org/ 10.1175/JCLI-D-14-00006.1.

— certainties for Extended Reconstructed Sea Surface Temperature (ERSST) version 4 (v4). J. Climate, 29, 3119-3142, https://doi.org/10.1175/JCLI-D-15-0430.1.

— Temperature, version 5 (ERSSTv5): Upgrades, validations, and intercomparisons. J. Climate, 30, 8179-8205, https:// doi.org/10.1175/JCLI-D-16-0836.1.

Kalnay, E., and Coauthors, 1996: The NCEP/NCAR 40-Year Reanalysis Project. Bull. Amer. Meteor. Soc., 77, 437-471, https:// doi.org/10.1175/1520-0477(1996)077<0437:TNYRP>2.0.CO;2.

Kao, H.-Y., and J.-Y. Yu, 2009: Contrasting eastern-Pacific and central-Pacific types of El Niño. J. Climate, 22, 615-632, https://doi.org/10.1175/2008JCLI2309.1.

Kug, J.-S., F.-F. Jin, and S.-I. An, 2009: Two types of El Niño events: Cold tongue El Niño and warm pool El Niño. J. Climate, 22, 1499-1515, https://doi.org/10.1175/2008JCLI2624.1.

— J. Choi, S.-I. An, F.-F. Jin, and A. T. Wittenberg, 2010: Warm pool and cold tongue El Niño events as simulated by the GFDL 2.1 coupled GCM. J. Climate, 23, 1226-1239, https:// doi.org/10.1175/2009JCLI3293.1.

Lander, M. A., 1994: An exploratory analysis of the relationship between tropical storm formation in the western North Pacific and ENSO. Mon. Wea. Rev., 122, 636-651, https://doi.org/ 10.1175/1520-0493(1994)122<0636:AEAOTR > 2.0.CO;2.

Lloyd, S., 1982: Least squares quantization in PCM. IEEE Trans. Inf. Theory, 28, 129-137, https://doi.org/10.1109/TIT.1982.1056489.

McKee, T. B., N. J. Doesken, and J. Kliest, 1993: The relationship of drought frequency and duration to time scales. Preprints, Eighth Conf. on Applied Climatology, Anaheim, CA, Amer. Meteor. Soc., 179-184.

McPhaden, M. J., S. E. Zebiak, and M. H. Glantz, 2006: ENSO as an integrating concept in Earth science. Science, 314, 1740 1745, https://doi.org/10.1126/science.1132588.

Murphy, B. F., S. B. Power, and S. McGree, 2014: The varied impacts of El Niño-Southern Oscillation on Pacific island climates. J. Climate, 27, 4015-4036, https://doi.org/10.1175/JCLI-D-13-00130.1.

Newman, M., M. A. Alexander, and J. D. Scott, 2011a: An empirical model of tropical ocean dynamics. Climate Dyn., 37, 1823-1841, https://doi.org/10.1007/s00382-011-1034-0.

— S.-I. Shin, and M. A. Alexander, 2011b: Natural variation in ENSO flavors. Geophys. Res. Lett., 38, L14705, https://doi.org/ 10.1029/2011GL047658.

Ropelewski, C. F., and M. S. Halpert, 1987: Global and regional scale precipitation patterns associated with the El Niño/ Southern Oscillation. Mon. Wea. Rev., 115, 1606-1626, https:// doi.org/10.1175/1520-0493(1987)115<1606:GARSPP>2.0.CO;2.

Schroeder, T. A., M. R. Chowdhury, M. A. Lander, C. C. Guard, C. Felkley, and D. Gifford, 2012: The role of the Pacific ENSO
Applications Climate Center in reducing vulnerability to climate hazards: Experience from the U.S.-Affiliated Pacific Islands. Bull. Amer. Meteor. Soc., 93, 1003-1015, https://doi.org/ 10.1175/BAMS-D-11-00109.1.

Scikit-Learn Developers, 2017a: K-Means clustering. Scikit-Learn, accessed 25 September 2017, http://scikit-learn.org/stable/ modules/generated/sklearn.cluster.KMeans.html.

2017b: Compute the silhouette coefficient for each sample. Scikit-Learn, accessed 14 December 2017, http://scikit-learn.org/ stable/modules/generated/sklearn.metrics.silhouette_samples. html\#sklearn.metrics.silhouette_samples.

Shea, E. L., and Coauthors, 2001: Preparing for a changing climate: The potential consequences of climate variability and change. Pacific Islands Regional Assessment Group Rep., 102 pp., http://scholarspace.manoa.hawaii.edu/bitstream/handle/10125/ 3404/pacific-climate-assessment.pdf.

Stuecker, M. F., F.-F. Jin, A. Timmermann, and S. McGregor, 2015: Combination mode dynamics of the anomalous northwest Pacific anticyclone. J. Climate, 28, 1093-1111, https://doi.org/ 10.1175/JCLI-D-14-00225.1.

Taschetto, A. S., and M. H. England, 2009: El Niño Modoki impacts on Australian rainfall. J. Climate, 22, 3167-3174, https:// doi.org/10.1175/2008JCLI2589.1.

Wang, B., and J. C. L. Chan, 2002: How strong ENSO events affect tropical storm activity over the western North Pacific. J. Climate, 15, 1643-1658, https://doi.org/10.1175/1520-0442(2002)015<1643: HSEEAT $>2.0 . \mathrm{CO} ; 2$

_ , and Q. Zhang, 2002: Pacific-East Asian teleconnection. Part II: How the Philippine Sea anomalous anticyclone is established during El Niño development. J. Climate, 15, 3252-3265, https:// doi.org/10.1175/1520-0442(2002)015<3252:PEATPI >2.0.CO;2. , and Q. Ding, 2008: The global monsoon: Major modes of annual variations in the tropics. Dyn. Atmos. Oceans, 44, 165183, https://doi.org/10.1016/j.dynatmoce.2007.05.002.

_ , R. Wu, and X. Fu, 2000: Pacific-East Asian teleconnection: How does ENSO affect East Asian climate? J. Climate, 13 1517-1536, https://doi.org/10.1175/1520-0442(2000)013<1517: PEATHD $>2.0 . \mathrm{CO} ; 2$

Wang, C., R. H. Weisberg, and J. I. Virmani, 1999: Western Pacific interannual variability associated with the El Niño-Southern Oscillation. J. Geophys. Res., 104, 5131-5149, https://doi.org/ 10.1029/1998JC900090.

Weng, H., K. Ashok, S. K. Behera, S. A. Rao, and T. Yamagata, 2007: Impacts of recent El Niño Modoki on dry/wet conditions in the Pacific rim during boreal summer. Climate Dyn., 29, 113-129, https://doi.org/10.1007/s00382-007-0234-0.

— , S. K. Behera, and T. Yamagata, 2009: Anomalous winter climate conditions in the Pacific rim during recent El Niño Modoki and El Niño events. Climate Dyn., 32, 663-674, https:// doi.org/10.1007/s00382-008-0394-6.

Yeh, S.-W., J.-S. Kug, and S.-I. An, 2014: Recent progress on two types of El Niño: Observations, dynamics, and future changes. Asia-Pac. J. Atmos. Sci., 50, 69-81, https://doi.org/10.1007/s13143-014-0028-3.

Yu, J.-Y., H.-Y. Kao, and T. Lee, 2010: Subtropics-related interannual sea surface temperature variability in the central equatorial Pacific. J. Climate, 23, 2869-2884, https://doi.org/ 10.1175/2010JCLI3171.1.

Yu, Z.-P., P.-S. Chu, and T. Schroeder, 1997: Predictive skills of seasonal to annual rainfall variations in the U.S.-Affiliated Pacific Islands: Canonical correlation analysis and multivariate principal component regression approaches. J. Climate, $\mathbf{1 0}$, 2586-2599, https://doi.org/10.1175/1520-0442(1997)010<2586: PSOSTA $>2.0 . \mathrm{CO} ; 2$. 